\title{
Organelle calcium-derived voltage oscillations in pacemaker neurons drive food-seeking behavior in Aplysia
}

Alexis Bédécarrats, Laura Puygrenier, John Castro O'Byrne, Quentin Lade, John Simmers, Romuald Nargeot

8 Univ. Bordeaux, INCIA, UMR 5287, F-33076 Bordeaux, France.

9 CNRS, INCIA, UMR 5287, F-33076 Bordeaux, France.

For correspondence:

14 Institut de Neurosciences Cognitives et Intégratives d'Aquitaine (INCIA)

15 Université de Bordeaux, CNRS - UMR 5287

16 Zone nord - bâtiment $2 A B$ - 2ème étage

17 BP 22

18146 rue Léo Saignat

1933076 BORDEAUX Cedex

20 E-mail: romuald.nargeot@u-bordeaux.fr 


\section{Abstract}

28 The expression of motivated behaviors depends on both external and internally-arising neural

29 stimuli, yet the intrinsic releasing mechanisms for such variably occurring behaviors remain

30 elusive. In isolated nervous system preparations of Aplysia, we have found that irregularly

31 expressed cycles of motor output underlying food-seeking behavior arise from regular

32 membrane potential oscillations of varying magnitude in an identified pair of interneurons

33 (B63) in the bilateral buccal ganglia. This rhythmic signal, which is endogenous and specific to

34 the B63 cells, is generated by organelle-derived intracellular calcium fluxes that activate

35 voltage-independent plasma membrane channels. The resulting voltage oscillation spreads

36 throughout a subset of gap junction-coupled buccal network neurons and by triggering plateau

37 potential-mediated bursts in B63, can initiate motor output driving food-seeking action. Thus,

38 an atypical neuronal pacemaker mechanism, based on rhythmic intracellular calcium store

39 release and intercellular propagation, can act as an autonomous intrinsic releaser for the 40 occurrence of a motivated behavior. 


\section{Introduction}

45 Motivated behaviors, such as feeding or sexual activity, are triggered by an interplay between

46 impulsive signals originating within the central nervous system (CNS), peripheral stimuli such as

47 sensory cues, and the positive or negative consequences of an act (Balleine, 2019; Berridge,

48 2019, 2004; Dickinson and Balleine, 1994; Fujimoto et al., 2019). This combination of flexible

49 extrinsic and intrinsic neural releasers determines both the likelihood of occurrence and the

50 selection of action patterns, which in turn imparts irregularity to the expressed goal-directed

51 behavior. However, depending on sensory experience motivated behaviors can be transformed

52 from variable to regular, rhythmically repeating action patterns that lead to the expression of

53 habits, routines, or compulsive behaviors. The production of such stereotyped repetitive

54 behavior, often reinforced by associative learning processes, is considered to become more

55 strongly dependent upon an automatic internally-arising drive and less sensitive to the sensory

56 consequences of the executed action (Balleine, 2019; Balleine and Dezfouli, 2019; Everitt and

57 Robbins, 2016, 2005). Although the contribution of internal drives to the induction of motivated

58 behavior is recognized, unanswered questions remain about their neural origin and whether

59 the highly flexible expression of a motivated behavior relies on similar inherent neuronal

60 processes as found for rhythmic behaviors generally (Grillner and El Manira, 2020; Marder et

61 al., 2015; Selverston, 2010; Steuer and Guertin, 2019).

A suitable animal model for addressing such issues is the sea slug Aplysia, in which

63 aspects of feeding behavior are generated by a well characterized neuronal network within the

64 buccal ganglia. In the absence of food stimuli, Aplysia spontaneously expresses food-seeking

65 behavior, which in addition to locomotor and head-waving movements, includes buccal and 
66 radula (a tongue-like organ) biting movements emitted at highly irregular intervals

67 (Kupfermann, 1974). This spontaneous and variable behavior can be regulated by operant-

68 reward conditioning that leads to the expression of regular and rhythmic biting movements

69 (Brembs et al., 2002; Costa et al., 2020; Nargeot et al., 2007; Sieling et al., 2014). Importantly,

70 neural correlates of this motivated behavior continue to be expressed by the underlying

71 neuronal network in the isolated buccal ganglia, thereby enabling the mechanisms responsible

72 for autonomously driving both the irregular and regular emissions of radula movement cycles

73 to be analyzed at the cellular and synaptic levels (McManus et al., 2019; Nargeot and Simmers,

74 2012). Identified components of this central pattern generator (CPG) circuit, such as the

75 electrically-coupled B63, B30, B31/32 neurons, were previously found to be essential

76 contributors to the decision-making process that drives radula motor output (Costa et al., 2020;

77 Hurwitz et al., 1997; Jing et al., 2004; Nargeot et al., 2009; Sieling et al., 2014; Susswein and

78 Byrne, 1988). Among these elements, the two bilateral B63 interneurons are the only cells

79 whose spontaneous production of an action potential burst is necessary and sufficient to trigger

80 each radula output cycle (Nargeot et al., 2009). Thus, deciphering the mechanisms underlying

81 the endogenous bursting activity of these key decision neurons is critical to understanding the

82 process of radula motor pattern expression. Although B63 bursting and buccal network activity

83 were previously found to rely on the cell's plateau potential-generating capability and its

84 electrical synapses with other circuit neurons (Sieling et al., 2014; Susswein et al., 2002), the

85 mechanism responsible for spontaneously triggering B63 plateaus and consequently the

86 irregular emission of motor output remains unknown. Our findings reported here indicate that

87 such motor pattern genesis relies on a voltage-insensitive pacemaker mechanism originating 
88 from organelle-driven fluxes in intracellular calcium that is specific to this homologous pair of

89 neurons.

90

91 Results

92 Motor output responsible for radula biting behavior, which in the absence of any food

93 stimulation consists of irregularly recurring cycles of radula protraction, closure and retraction

94 (Figure 1A), continues to be expressed by identified CPG circuitry in isolated buccal ganglia

95 (Figure 1B) and can be recorded from the corresponding buccal motor nerves (Figure 1C).

96 Individual radula bites are instigated by synchronous impulse burst activity in the two bilateral,

97 electrically-coupled B63 interneurons that via electrical and chemical synapses with their ipsi-

98 and contralateral buccal network partners, are able to trigger the two-phase buccal motor

99 pattern (BMP) for a bite cycle (Figure 1C) (Hurwitz et al., 1997; Nargeot et al., 2007; 2009). This

100 essential role played by B63 is partly mediated by a bistable membrane property, which allows

101 the sudden switching of the neuron's resting membrane potential to a depolarized plateau that

102 activates a high frequency burst of action potentials (Susswein et al., 2002). Consistent with this

103 property's regenerative nature, a brief intracellular injection of depolarizing current into an

104 otherwise silent B63 neuron can initiate a plateau potential and accompanying burst discharge,

105 which in turn activates the contralateral B63 cell and elicits a single BMP by the buccal CPG

106 network (Figure 1D).

107

108 A rhythmic oscillatory drive underlies irregular BMP genesis 
109 To investigate the mechanism(s) responsible for spontaneously instigating B63's plateau

110 potentials and resulting BMPs, we first sought evidence for an underlying triggering process in

111 stable intracellular recordings from this neuron in still active isolated buccal ganglia $(\mathrm{N}=26)$ in

112 the absence of any electrical or chemical stimulation. Such recordings (episodes of $>10$ min per

113 cell) revealed that B63's membrane potential underwent continuous depolarizing fluctuations

114 over time (Figures 1C, 2A), many of which remained below threshold for action and plateau

115 potential generation. Others of these low-amplitude depolarizations elicited isolated action

116 potentials without a plateau potential, whereas the remainder were associated with the

117 production of a plateau potential and the expression of a BMP. Consequently, B63's plateau

118 potentials and fictive bite cycles were spontaneously generated at irregular time intervals

119 ranging from several seconds to a minute.

120 Although B63's widely variable plateauing activity was expressed in an apparently

121 random manner, we next asked whether its recurrence was associated with a specific temporal

122 organization in the cell's membrane potential fluctuations. To assess this possibility, Fourier

123 (spectral) analysis (see Material and Methods) was applied to 10 min excerpts of the 26 B63 cell

124 recordings. As seen in the spectral density periodogram for the B63 neuron illustrated in Figure

$1252 \mathrm{~A}$, the cell's spontaneous membrane potential changes decomposed into two distinct

126 periodicities with peaks at $61 \mathrm{~s}$ and $144 \mathrm{~s}$, respectively (Figure 2B, upper panel; Supplemental

127 Figure 1). Moreover, a mathematical reconstruction based on these dominant periods showed

128 that the slower waveform was mostly correlated with the largest membrane potential

129 depolarizations that led to plateau potentials and the production of BMPs (Figure 2C). In

130 contrast, the faster waveform was timed with virtually all membrane voltage changes, including 
131 the subthreshold fluctuations and events associated with isolated action potentials or plateau

132 potential-driven bursts.

The faster of the two periodicities (mean \pm CI95, $58 \pm 5 \mathrm{~s}$ ) varied relatively little between

134 different preparations, as evidenced by the sharper spectral density peak in the averaged

135 periodogram for all 26 buccal preparations (Figure 2B, lower panel). In contrast, the broader

136 peak of the slower rhythm (mean \pm Cl95, $146 \pm 23 \mathrm{~s}$ ) was indicative of the wide variability in

137 occurrence of plateau potentials over time and between preparations. Moreover, for both

138 rhythms, the considerable variability in their power spectral magnitudes $\left(1592 \pm 650 \mathrm{mV}^{2} . \mathrm{s}\right.$,

$1391524 \pm 676 \mathrm{mV}^{2} . \mathrm{s}$; mean $\pm \mathrm{Cl95 \%}$, respectively) was attributable to the large amplitude

140 variations between spontaneous membrane depolarizations that succeeded or failed to trigger

141 plateau potentials in the different preparations (see also, Supplemental Figure 1A , B).

142 To further characterize the temporal nature of B63's faster oscillatory rhythm, spectral

143 analysis was performed on cells $(N=14)$ that did not produce plateau potentials and resultant

144 BMPs throughout $10 \mathrm{~min}$ recording sequences. Such non-plateauing neurons continued to

145 express repetitive, now uniquely sub-threshold, membrane depolarizations (Figure 2D) that

146 again were clearly rhythmic as revealed by the single dominant peak both in individual (Figure

$1472 \mathrm{E}$, top). and averaged periodograms of the 14 recorded neurons (Figure 2E, bottom).

148 Moreover, the mean period ( \pm C195\%) of this solitary rhythm (69 \pm 7 s) was within a range

149 equivalent to that of the faster oscillatory waveform found in B63 neurons that additionally

150 expressed plateaus (cf, Figure 2E, B). Although the magnitude of the remaining subthreshold

151 rhythm varied over time and between preparations (Figure 2E, Supplemental Figure 1B), as also 
152 evidenced by waveform reconstruction (Figure 2F), it had a much smaller amplitude than the

153 corresponding waveform in plateau-active cells.

154 Altogether, these results show that the B63's spontaneous bioelectrical behavior

155 includes a rhythmic depolarizing signal that can remains below threshold for neuronal

156 excitability or, in an apparently random manner, can lead to action and plateau potential

157 production. However, despite their irregularity, the expression of plateau potentials, and

158 resultant BMPs, is also inscribed with a periodicity, albeit considerably slower and more

159 variable than the underlying oscillation.

160

161 The voltage oscillation is endogenous to B63 and drives plateauing

162 In principle, the low amplitude oscillation of the B63 neurons could originate extrinsically from

163 a presynaptic source, or derive intrinsically from a rhythmogenic property inherent to the

164 neurons itself. Although no other buccal ganglia cell has been found to provide such a synaptic

165 drive, we distinguished between these two possibilities by recording B63 cells in isolated

166 preparations in which chemical synapses were blocked by bath perfusion of a modified saline

167 containing a low calcium concentration (3 mM) and $10 \mathrm{mM}$ cobalt, a nonspecific calcium

168 channel blocker.

169

The application of such 'Low Ca+Co' saline soon induced a prolonged depolarization of

170 recorded $\mathrm{B} 63$ neurons (Figure 3A), then after ca. 20 min, which was necessary to fully block

171 chemical synapses - as confirmed by the suppression of the excitatory synapse between B63

172 and a contralateral B31 neuron (data not shown) - the membrane potential repolarized to its

173 initial level. Significantly, these neurons thereafter continued spontaneously to express a low- 
174 amplitude oscillation for $>1.5 \mathrm{hrs}$, although its magnitude gradually decreased over time (see

175 Supplemental Figure 6A). As in normal saline conditions, the cyclic depolarizations were either

176 sub- or supra-threshold for spike generation, or at irregular intervals, were associated with

177 plateau potentials and high frequency bursts (Figure 3A, B; Supplemental Figure 2).

recording periods after chemical synapse blockade in 15 buccal ganglia preparations revealed

180 that, as in ASW conditions, B63's membrane potential fluctuations decomposed into two major

181 periodicities (Figure 3B, C and Supplemental Figure 1C). The periodograms and corresponding

182 waveform reconstructions indicated that the slowest oscillation (mean period \pm Cl95\%: $274 \pm 61$

$183 \mathrm{~s}$ ) of large magnitude (mean spectral density \pm Cl95\%: $11587 \pm 5741 \mathrm{mV}^{2} . \mathrm{s}$ ) was mainly

184 associated with the expression of plateau potentials. The fastest oscillation (mean period \pm

185 Cl95\%: $104 \pm 12$ s) of smaller amplitude (mean spectral density \pm Cl95\%: $4640 \pm 3341 \mathrm{mV}^{2} . \mathrm{s}$ )

186 corresponded to rhythmic depolarizations that remained subthreshold, or were associated

187 either with low frequency spiking or plateau driven bursts. As found in unblocked ganglia, this

188 faster periodicity was more clearly evident when plateauing was absent: in 10 of the 15 buccal

189 ganglia, B63 failed to produce plateaus during at least $10 \mathrm{~min}$ of analyzed recording excerpts,

190 although these neurons continued to spontaneously express a rhythmic subthreshold

191 oscillation (Figure 3D, E and Supplemental Figure 1D). Again, the mean cycle period of this

192 solitary waveform ( \pm C195\%: $98 \pm 8$ s) was similar to that of the faster rhythm when plateau

193 potentials also occurred (cf., Figure 3B, C).

194 Thus, although blocking chemical synapses led to variations in mean cycle periods,

195 amplitudes and plateau durations, B63's spontaneous voltage fluctuations still expressed two 
distinct oscillatory states, indicating that both processes occur independently of chemical

197 synaptic inputs. Furthermore, inspection of the superimposed reconstructions of these

198 oscillations under Low Ca+Co (Figure 3B), as in ASW (see Figure 2C), indicated that the onset of

199 each plateau potential was invariably associated with a depolarizing phase of the faster

200 oscillation, suggesting that the latter endogenous signal might be responsible for triggering the

201 former.

202

This initiating process was further indicated by comparing the kinetics of B63's

203 spontaneous voltage changes during subthreshold cycles of oscillation with those associated

204 with plateaus. From recordings under both synaptic blockade (Figure 4A,B) or normal saline

205 conditions (Supplemental Figure 3A), the superposition of single cycles with and without

206 plateau potential occurrences indicated that the relatively fast rising phases of the two events

207 shared similar trajectories. In the absence of a plateau potential, this initial depolarization could

208 trigger large amplitude impulse firing, or when a plateau occurred, it emerged as an additional

209 and sustained (lasting tens of seconds) depolarization of $20-30 \mathrm{mV}$ that in turn elicited a high

210 frequency burst of low amplitude action potentials. The relationship between the voltage

211 oscillation and plateauing in both Low Ca+Co and ASW conditions was quantified by phase

212 plane analysis, which enables visualizing the voltage trajectory of neuronal oscillatory activity

213 independent of time. To this end, recordings from B63 were low pass filtered to remove action

214 potentials, then membrane voltage was plotted against the first derivative dV/dt, which is

215 proportional to the net membrane ionic current (Zhu et al., 2016). Such phase-plane plots from

216 data excerpts of the same neurons under synaptic blockade (Figure 4C) or unblocked conditions

217 (Supplemental Figure 3B) clearly showed a close coincidence between the early depolarizing 
218 trajectories of the spontaneous oscillation whether they developed (black spirals) or not (red

219 spirals) into a sustained plateau. Subsequently, depending on the membrane potential reached

220 at the end of this initial phase, the level of which varied considerably from one cycle to another,

221 the trajectories bifurcated to give rise either to the large and stereotyped voltage changes of

222 plateau potentials, or if subthreshold, immediately spiraled back to the baseline potential.

223 Therefore, together these results support the conclusion that rather than being

224 instigated by chemically-mediated synaptic inputs, the repeated expression of plateau

225 potentials by the B63 neuron is a direct consequence of a spontaneous membrane voltage

226 oscillation of irregular magnitude originating from within the cell itself.

228 The oscillatory mechanism is not voltage-dependent

229 A classical diagnostic feature of endogenous neuronal oscillators, the inherent rhythmogenic

230 capability of which typically derives from voltage- and time-dependent membrane channels, is

231 a sensitivity of cycle frequency and mode of firing to different levels of membrane polarization

232 (Bal et al., 1988; Canavier et al., 1991; Mathieu and Roberge, 1971). We therefore tested the

233 voltage-dependence of B63's oscillatory mechanism by manipulating the cell's membrane

234 potential during intracellular recordings from buccal ganglia exposed to Low Ca+Co saline. As

235 described earlier in this condition, B63 neurons continued spontaneously to generate a voltage

236 oscillation that included both subthreshold depolarizations and less frequent plateau potentials

237 with accompanying intense bursts of impulses (Figure 5A, left). As seen in Figure 5A (right), a

238 continuous experimental hyperpolarization by intracellular current injection suppressed the

239 expression of plateau potentials, but with no observable effect on the frequency of the 
240 underlying oscillation. The latter remained similar to that expressed before the imposed

241 hyperpolarization where individual depolarizing cycles were strictly time-locked with the raising

242 phase of each plateau potential (see arrowheads in Figure 5A, left). These findings were

243 therefore in accordance with the all-or-none, voltage-sensitivity of B63's plateau potentials that

244 are activated by the low-amplitude voltage oscillation. They also indicated that the latter's cycle

245 period is unaffected by a change in membrane potential either in response to experimental

246 manipulation or during the plateau potentials themselves.

This voltage-insensitivity of B63's low amplitude oscillation was further established by

248 comparing the effects of the same imposed membrane potential changes in different

249 preparations. Using two-electrode current-clamp in 7 preparations, B63 was initially held at -70

$250 \mathrm{mV}$, a potential that was subthreshold for plateau genesis, and subsequently further

251 hyperpolarized to $-80 \mathrm{mV}$. No significant change in oscillation cycle period resulted from this

252 hyperpolarization (Figure $5 B, C ; V=16, p=0.799$ ). Similarly, in 9 preparations continuous

253 depolarizing current injection that shifted B63's membrane potential from $-70 \mathrm{mV}$ to $-30 \mathrm{mV}$

254 also had no significant effect on the period of ongoing oscillation (Figure 5D, E; $V=28, p=$

255 0.553). In contrast to the cycle period, however, in the same experiments the amplitude of

256 B63's oscillation was found to increase (Figure 5B) or decrease (Figure 5D) according to the sign

257 of injected current. Presumably this was due to the membrane potential shifting relative to the

258 reversal potential of the depolarizing inward currents producing the oscillation (see below).

259 Finally, very similar observations were made from a different set of B63 neurons also recorded

260 in unstimulated buccal ganglia but which remained under ASW (data not shown), thereby 
261 confirming that the cell's voltage-independent oscillation was a spontaneous emergent

262 property regardless of whether the buccal network remained functionally reduced or intact.

263 Altogether, these results are consistent with an expected contribution of intrinsic,

264 voltage-dependent channels to plateau potential genesis in the B63 neuron, and confirm that

265 they are triggered by the underlying voltage oscillation. On the other hand, however, our data

266 show that the mechanism responsible for the oscillation itself does not rely on an activation of

267 voltage-dependent ion channels in the neuron's membrane.

\section{Circuit-wide voltage oscillation via gap-junction coupling}

270 Although chemical synaptic interactions with other buccal network neurons are not responsible

271 for generating B63's low-amplitude voltage oscillation, the possibility remained that it

272 originates extrinsically and is conveyed to B63 through electrical synapses, which are

273 widespread in buccal CPG circuitry. To assess this possibility, simultaneous intracellular

274 recordings of $\mathrm{B} 63$ with at least one another electrically-coupled neuron of the buccal CPG

275 network (see Figure 1B) were made under Low Ca+Co saline. Because the B63, B31 and B30

276 neurons in each of the bilateral ganglia are major components of the radula protraction

277 generator subcircuit and share strong electrical synapses (Hurwitz et al., 1997; Nargeot et al.,

278 2007) these three cell types were chosen for paired recordings. Other protraction generator

279 neurons electrically coupled with B63, such as B34, B65, were also occasionally recorded, while

280 B8 radula closure motor neurons, which are connected to these neurons via chemical, but not

281 any electrical, synapses were used as a control (Costa et al., 2020). 
Paired recordings from the bilateral B63 neurons, which are themselves electrically

283 coupled, revealed that the two cells express almost identical low-amplitude oscillations that

284 occur in strict synchrony (Figure 6A). However, action and plateau potentials, whose expression

285 presumably depends on individual cell excitability, occurred independently. Moreover, within a

286 same ganglion, B31 and B30 neurons belonging to the protraction generator and electrically

287 coupled with the ipsilateral B63 also expressed a voltage oscillation in time with that of the

288 latter (Figure 6B; Supplemental Figure 4). In contrast, B8 motor neurons, which are not coupled

289 with B63 or the other protraction generator neurons, did not express any such oscillation

290 (Figure 6C).

291 The amplitudes and phase relationships of the low-amplitude voltage oscillations in

292 neuronal pairs were next quantified by spectral analysis over 5 successive cycles during which

293 no plateauing occurred. The oscillation magnitude was determined from the peak spectral

294 density of the single dominant period in the corresponding power spectrum (see Supplemental

295 Figure 1D). For homologous bilateral neurons, no significant difference in oscillation amplitude

296 was found between either the B63 or B31 cell pairs (Figure 6D, left; B63/B63, V = 22, $p=0.625$;

297 B31/B31, $V=13, p=0.687)$. However, comparison between heterologous neuron pairs within a

298 same ganglion showed that the oscillation magnitude was significantly greater in B63 than in

299 either the ipsilateral B31 or B30 cells (B63/B31, $V=78, p<0.001 ; B 63 / B 30, V=36, p<0.01$ ) and

300 predictably, in B8 motor neurons (Figure 6D, middle and right; also see 6B and Supplemental

301 Figure 4).

302

Bivariate cross-waveform analysis of the same recordings revealed no significant phase

303 difference in the voltage oscillations of homologous cell pairs, either between the two B63 or 
304 B31 neurons, in bilateral ganglia (Figure 7A, C; B63/B63, $V_{0}=31, p=0.769 ; B 31 / B 31, V_{0}=15, p$

$305=0.437)$. Unexpectedly, however, in heterologous ipsilateral pairs, B63's oscillation was found

306 to be significantly phase-advanced by several seconds compared to the accompanying

307 oscillation of either the B31 or B30 neurons (Figure $7 \mathrm{~B}, \mathrm{C} ; \mathrm{B} 31 / \mathrm{B} 63, \mathrm{~V}_{0}=78, \mathrm{p}<0.001 ; \mathrm{B} 30 / \mathrm{B} 63$,

$\left.308 V_{0}=35, p<0.02\right)$. Moreover, group pair-wise comparisons indicated that the oscillation phase

309 was also significantly different between the different cell combinations $(H=20.947, p<0.001)$,

310 specifically, between homologous and heterologous pairs (B63/B63 vs B31/B63: $q=6.986, p<$

$3110.001 ; B 63 / B 63$ vs B30/B63: $q=8.263, p<0.001 ; B 31 / B 31$ vs B31/B63: $q=-5.064, p<0.01$;

312 B31/B31 vs B30/B63: $q=-6.407, p<0.005)$. In contrast, no significant phase differences were

313 found between either homologous or between heterologous cell pairs (B63/B63 vs B31/B31: q

$314=0.889, \mathrm{p}=0.922 ; \mathrm{B} 31 / \mathrm{B} 63$ vs $\mathrm{B30} / \mathrm{B} 63: \mathrm{q}=2.034, \mathrm{p}=0.486)$.

315 These findings thus showed that a spontaneous membrane potential oscillation is not

316 restricted to the $\mathrm{B} 63$ neurons, but extends to all other neurons with which these two cells are

317 electrically-coupled in the radula protraction generator circuit. The voltage oscillations in

318 homologous cells in the two hemi-ganglia are synchronous and with similar amplitudes.

319 However, within a given ganglion, each cycle of oscillation is expressed earlier in B63 and with a

320 greater magnitude than in any of the cell's network partners. These relative timing and

321 amplitude differences therefore support the conclusion that the voltage oscillation is not an

322 equivalent emergent property of a network of electrically-coupled neurons, but rather,

323 originates in the two B63 cells and then spreads, presumably via gap junctional connections

324 with adjacent cells, throughout the remaining circuit. 


\section{Involvement of cation channels and organelle signaling in B63's oscillation}

327 As reported above, an experimental depolarization of B63 decreased the amplitude of its

328 spontaneous voltage oscillation, indicating a reversal potential for the underlying ionic currents

329 above $-30 \mathrm{mV}$ (see Figure 5D), which in turn suggested the involvement of sodium and/or

330 calcium conductances in the oscillation. To test this likelihood, we examined three groups of 6

331 isolated buccal ganglia that were all initially bathed in Low Ca+Co saline to block chemical

332 synapses. In a first group, the sodium channel blocker, TTX (50 $\mu \mathrm{M})$, was then added to the

333 bathing solution; in a second 'sodium free' group, the ganglia were exposed to a modified

334 Low+Ca saline in which sodium was replaced by choline, a non-permeable cation; in a third

335 'calcium-free' group, the initial saline was replaced by a solution lacking any calcium and 336 containing the calcium chelator EGTA $(0.5 \mathrm{mM})$.

As evidenced by the individual cell recordings in Figure $8 \mathrm{~A}-\mathrm{C}$, the voltage oscillation of

338 the B63 neurons was reversibly abolished by exposure to each of the three salines. This

339 suppression was quantified in the 18 recorded neurons by making a paired comparison of their

340 peak spectral densities in 10 min data excerpts obtained before and after 10 min of modified

341 saline application (Figure 8D). In all cases, the initial dominant oscillation was significantly

342 diminished in each of the saline conditions (TTX: V =21, $p<0.05$; Sodium-free: $V=21, p<$

343 0.05; Calcium-free: $V=21, p<0.05)$. A noticeable difference, however, was that from the

344 instant when observable saline effects began to occur, the time course of this suppression

345 varied considerably according to the saline condition. Whereas B63's oscillation terminated

346 totally and abruptly in TTX-containing and Na-free salines (Figure 8A, B), with the same rate of

347 calcium-free perfusion, the oscillation persisted after an effect first became evident, damping 
348 slowly until its full suppression several minutes later (Figure $8 \mathrm{C}$ ). This difference in oscillation

349 longevity is further evident in the group analysis of Figure $8 \mathrm{E}$, which compares the time until

350 the oscillation ceased when measured from the onset of each modified saline's perfusion.

351 Again, suppression took significantly longer in the Ca-free saline as compared to either the TTX-

352 containing or Na-free conditions $(H=11.684, p<0.001$; Ca-free vs TTX: $q=4.624, p<0.05$ and

353 Ca-free vs Na-free: $q=8.092, p<0.001)$, which themselves were not significantly different $(q=-$

$3543.468, p=0.07)$.

These results are therefore consistent with sodium and calcium ions play a critical role

356 in B63's spontaneous voltage oscillation, although their contributions appear to be

357 fundamentally different. The rapid and full suppression of the oscillation in sodium-free or TTX-

358 containing salines, both of which contained calcium, indicated that TTX-sensitive sodium

359 channels are essential to producing the oscillation. By contrast, its slow decline in the absence

360 of extracellular calcium is not consistent with a primary role of transmembrane calcium influxes

361 in oscillation genesis per se. Rather, although necessary for oscillation, calcium may act in an

362 underlying regulatory process involving the dynamics of intracellular calcium and its control by

363 intracellular stores, and that this signal is temporarily preserved after the cation's extracellular

364 removal as the store calcium gradually runs down until depletion.

The main organelles that regulate intracellular calcium concentration are the

endoplasmic reticulum (ER) whose membrane carries calcium channels, the calcium-ATPase

367 reuptake pump (SERCA) and calcium release channels (the inositol triphosphate (IP3) and

368 ryanodine (Ry) receptors), and mitochondria that act in energy supply as well as calcium

369 sequestration and release (Groten et al., 2013). To test the implication of ER and mitochondrial 
370 calcium in B63's voltage oscillation, isolated buccal ganglia $(\mathrm{N}=6)$ were bathed in Low Ca+Co

371 saline before and after addition of $20 \mu \mathrm{M}$ CPA, a selective inhibitor of SERCA (see Materials and

372 Methods). In a second group of ganglia, $(N=6)$, the same protocol was used, but with the

373 addition of $20 \mu \mathrm{M}$ FCCP, an oxidative phosphorylation uncoupling agent that leads to calcium

374 release from mitochondrial stores. From intracellular recordings of B63 neurons in these

375 preparations, peak spectral density magnitudes during a 10 min excerpt before drug application

376 - and in the absence of plateau potentials - were compared to those computed over a 10 min

377 period that began 20 min after the start of drug perfusion.

378

Bath perfusion of CPA caused a progressive and complete, but reversible, suppression of

379 B63's voltage oscillation in association with a slight, but consistent, gradual membrane

380 depolarization (Figure 9A). The application of FCCP also completely, although irreversibly,

381 suppressed the oscillation that was now accompanied by a stronger sustained depolarization of

$382 \sim 10-20 \mathrm{mV}$ (Figure 9C). No such change in B63's voltage oscillation or baseline membrane

383 potential resulted from perfusion of either Low $\mathrm{Ca}+\mathrm{Co}$ alone or this saline containing solely the

384 DMSO vehicle (Supplemental Figure 5). A within group analysis of peak spectral densities before

385 vs during drug application confirmed that exposure to CPA or FCCP significantly reduced the

386 oscillation amplitude of all the recorded B63 neurons (Figure 9B, D; CPA: V = 21, p < 0.05; FCCP:

$387 \mathrm{~V}=21, \mathrm{p}<0.05)$. The peak spectral density reduction was also significantly different between

388 both the CPA and FCCP experimental groups and neurons exposed to DMSO alone, but not

389 between the CPA and FCCP groups themselves $(H=11.415, p<0.01 ;$ CPA vs DMSO: $q=7.018, p$

$390<0.001 ;$ FCCP vs DMSO: $q=6.517, p<0.001 ;$ CPA vs FCCP: $q=0.501, p=0.933)$. 
These data are therefore consistent with the hypothesis that intracellular organelles

392 play an important role in generating the B63 neuron's low-amplitude voltage oscillation by a 393 dynamic regulation of intracellular calcium concentration via the release of store calcium and

394 its sequestration mediated by ATP-dependent pumps. Depletion of mitochondrial calcium

395 (induced by FCCP) or of ER calcium by an impairment of reuptake pumps (by CPA) would be 396 expected to block this dynamic, leading to a rise in intracellular calcium levels and a resultant 397 tonic cell membrane depolarization, which is precisely what we observed in the experiments 398 reported above (see Figure 9A, C).

399 To further establish the ER's involvement in B63's voltage oscillation, a final series of

400 experiments were conducted in which we assessed the effects of blocking the membrane

401 calcium channels of the organelles themselves. This was achieved by pressure injecting heparin

402 (20 mg/ml), a well-known non-permeable IP3 receptor antagonist (Bezin et al., 2008), into the 403 somata of either bilateral pairs of B63 neurons, or their two B31 network partners. After 30 min 404 injection, simultaneous intracellular recordings were made from heterologous B63 and B31 cell 405 pairs under Low Ca+Co saline conditions. Heparin injection into the two B31 neurons had no 406 effect on the ongoing voltage oscillation of either a heparin-injected B31 itself or its non407 injected B63 partner (Figure 10A). In contrast, the reverse experiment that consisted of 408 injecting the IP3 receptor antagonist into the two B63 neurons caused a drastic reduction in the 409 spontaneous oscillation, both of one of the injected B63 cells and a recorded B31 partner 410 (Figure 10C). These findings were further supported by spectral analysis of recording excerpts 411 from B63 cells in the two groups of preparations after bilateral B31 $(N=4)$ or B63 $(N=5)$ 412 heparin injection. Recorded B63 neurons continued to express a distinct voltage oscillation with 
413 a mean period of $67 \pm 3.2 \mathrm{~s}$ when heparin was injected into the two B31 cells (Figure 10B), but

414 this dominant oscillation disappeared with heparin's presence in the B63 neurons (Figure 10D).

415 Therefore, in addition to the participation of ER calcium sequestering pumps, organelle calcium

416 release via IP3-dependent calcium channels evidently contributes to the voltage oscillation of

417 buccal CPG network neurons. Significantly moreover, these results further demonstrated that

418 the voltage oscillation's origin is specific to the B63 neurons, the sole necessary and sufficient

419 elements for triggering the BMPs that drive radula food-seeking movement. 


\section{Discussion}

422 This study aimed to decipher the basic neuronal mechanisms underlying a central network's

423 ability to generate the impulsive motor drive for an aspect of Aplysia's food-seeking behavior.

424 Our findings indicate that this highly irregular motivated act arises from an atypical endogenous

425 pacemaker property of a homologous pair of decision-making interneurons belonging to the

426 animal's buccal feeding network. The cell-specific pacemaker signal does not derive from an

427 oscillatory mechanism based on voltage-dependent ionic currents, as is usually found, but

428 rather depends on a cyclic release/reuptake of calcium from intracellular stores acting on

429 voltage-insensitive membrane channels. The resultant low amplitude oscillation of the decision

430 neurons' membrane potential, which is spontaneously expressed with a regular period but a

431 varying magnitude, is spread to gap junction-coupled network partners. Depending on the

432 membrane potential reached during the depolarizing phase of a given oscillation cycle, a

433 prolonged plateau and accompanying spike burst may be initiated, which in turn elicits network

434 output for a cycle of food-seeking movement. The intracellular calcium oscillation originating in

435 two key circuit neurons thus provides a continuous rhythmic carrier signal from which burst-

436 generating plateau potentials necessary for behavioral action can sporadically arise.

\section{Intracellular calcium oscillation as a neuronal pacemaker mechanism}

439 The endogenous oscillatory capability of invertebrate and vertebrate neuronal pacemakers is

440 mainly attributed to sets of plasma membrane ion channels whose specific functional

441 properties allow the production of cyclic membrane depolarization/repolarization and

442 associated impulse bursting (Adams and Benson, 1985; Brocard et al., 2013; Calabrese, 1995; 
443 Chevalier et al., 2016; Golowasch et al., 2017; Harris-Warrick, 2002; Selverston, 2010). Although

444 this pacemaker mechanism can be regulated by second-messenger cascades and cytosolic

445 calcium released from intracellular stores, its expression relies essentially on the voltage-

446 sensitivity of the membrane channels themselves (Butera et al., 1996; Canavier et al., 1991;

447 Kadiri et al., 2011; Liu et al., 1998; Yu et al., 2004). Thus, depending on membrane potential

448 levels, the cycle frequency of the endogenous voltage oscillation can be modified, thereby

449 changing the frequency of the effector rhythm in which the pacemaker cell is involved

450 (Canavier et al., 1991; Chevalier et al., 2016; Koshiya and Smith, 1999; Miller and Selverston,

451 1982). Spontaneous neuronal oscillations can also be generated by voltage-independent

452 pacemaker mechanisms involving plasma membrane ionic pumps, such as $\mathrm{Na} / \mathrm{K}$ ATPase, which

453 periodically repolarize the membrane of bursting neurons (Darbon et al., 2003; Johnson et al.,

454 1992; Kueh et al., 2016). Such pump-driven oscillations require tonic cellular activation or

455 disinhibition and are not blocked by extracellular calcium removal or Na channel blockers such

456 as TTX.

An increasing body of evidence from studies on endocrine, muscle and non-excitable

458 tissues (Baker et al., 2016; Fridlyand et al., 2010; Vinogradova et al., 2005; Zhou et al., 2019),

459 but also in early developing neurons (Gu et al., 1994), has indicated that a slow oscillatory cell

460 signal with cycle periods of seconds to several minutes can be generated spontaneously by

461 organelle-derived fluctuations in intracellular calcium concentration. Such a rhythmic calcium

462 dynamic, involving notably the endoplasmic reticulum and mitochondria, may be a source of

463 plasma membrane voltage oscillation without the participation of voltage-sensitive ion

464 channels. Specifically, the oscillation arises from a periodic accumulation/removal of 
465 cytoplasmic calcium, principally by IP3 and Ry receptor-mediated calcium efflux and ATP-

466 dependent pump-mediated influx across the store membrane, which in turn is translated into a

467 voltage signal by an activation of calcium-sensitive channels at the plasma membrane

468 (Fridlyand et al., 2010; Hickey et al., 2010; van Helden et al., 2000; Vinogradova et al., 2005).

In a corresponding and novel manner for a neuronal system, our present data indicate

470 that an intracellular calcium wave generated by organelle calcium release and reuptake is

471 responsible for the spontaneous low-amplitude voltage oscillation observed in B63 neurons.

472 First, experimental manipulation of the cell's membrane potential over voltage ranges where

473 most voltage-dependent channels would be expected to be closed had no effect on either the

474 occurrence or frequency of this persistent oscillation. Second, at variance with a possible

475 essential contribution of plasma membrane sodium or calcium pumps, the voltage oscillation

476 was suppressed in TTX-containing saline and its magnitude increased, rather than decreased, as

477 would be expected with low extracellular calcium concentrations. Third, the voltage oscillation

478 was suppressed with pharmacological treatments that inhibit IP3 receptors, block SERCA pumps

479 involved in transporting calcium into the endoplasmic reticulum, and disrupt energy production

480 and calcium storage by mitochondria. Finally, the slow and gradual suppression of the voltage

481 oscillation observed during prolonged exposure to calcium-free saline was commensurate with

482 a progressive depletion of store calcium. Presumably, the primary intracellular calcium dynamic

483 drives plasma membrane voltage oscillation by activating calcium-sensitive and voltage-

484 insensitive sodium or other cation channels (Hickey et al., 2010; Kadiri et al., 2011; Kramer and

485 Zucker, 1985), without excluding the possibility that B63's membrane carries other burst-

486 generating oscillatory properties (Costa et al., 2020; Nargeot et al., 2009; Susswein et al., 2002). 
487 Indeed, in contrast to the organelle-derived oscillatory mechanism reported here, where B63

488 was behaving spontaneously in the absence any experimental stimulation, this cell also

489 possesses an oscillatory bursting capability that does rely on voltage-dependent ion channels

490 (Nargeot et al, 2007; 2009; Sieling et al, 2009). However, this latter mechanism is activated only

491 when the cell is conveyed to more depolarized levels by sensory-induced changes in excitability

492 or in response to direct current injection. This state-dependent expression of two different

493 burst-generating processes by the B63 neuron is therefore reminiscent of the multiple

494 rhythmogenic ionic mechanisms reported in other oscillatory neurons, where each

495 mechanism's participation varies according to different stimulus conditions (Harris-Warrick and

496 Flamm, 1987; Kadiri et al., 2011; Peña et al., 2004).

\section{Variability in motor pattern emission with a periodic pacemaker mechanism}

499 Irregularity in the expression of motor activity is a fundamental feature of motivated or goal-

500 directed exploratory behaviors, including Aplysia's food-seeking movements, when animals are

501 faced with an uncertain surrounding environment. Although such motor variability is partly

502 dictated by peripheral sensory inputs (Cullins et al., 2015; Lyttle et al., 2017; McManus et al.,

503 2019; Pearson, 2000; Tam et al., 2020; Wimmer et al., 2015), it also depends on the functional

504 properties of the central networks and constituent neurons producing the behavior (Sims et al.,

505 2019). In this context, random processes such as stochastic variations in the activation of

506 intrinsic and voltage-dependent properties of individual neurons and synaptic noise can be

507 sources of variability in motor output expression (Carroll and Ramirez, 2013; Darshan et al., 508 2017; Melanson et al., 2017; Nargeot et al., 2009; Zhang et al., 2020). Moreover, modelling 
509 evidence has suggested that an aperiodicity in slow cytosolic calcium dynamics can lead to

510 irregular voltage oscillations in otherwise regularly bursting CPG neurons (Falcke et al., 2000). In

511 contrast, our experimental data indicate that spontaneous and irregular motor pattern genesis

512 can derive from a cell-specific pacemaker mechanism involving an intracellular calcium dynamic

513 that itself is strictly periodic, but where randomness arises from cycle-to-cycle variations in the

514 amplitude of the rhythmic membrane depolarizations it produces. By oscillating close to the

515 threshold for voltage-dependent plateau potential genesis required for CPG circuit output,

516 these low-amplitude depolarizations thereby determine the variability with which Aplysia's

517 exploratory movements are expressed. Timing irregularity would be further reinforced by an

518 interaction between the differing dynamics of the organelle-derived and voltage-dependent

519 oscillatory mechanisms that coexist in the B63 neuron as mentioned above.

$520 \quad$ Magnitude alterations in cytosolic calcium fluxes and resultant plasma membrane

521 voltage changes can arise from an interaction between different dynamic processes. Such

522 variability could result from a direct interplay between the different intracellular calcium stores

523 themselves (Geiger and Magoski, 2008; Groten et al., 2013; Haberichter et al., 2001; Hajnóczky

524 et al., 1995; Wacquier et al., 2019, 2016) or from an interaction between the store-generated

525 calcium oscillation and extracellular calcium influxes (Chay, 1996a; Falcke et al., 2000; van

526 Helden et al., 2000). Furthermore, voltage amplitude irregularity could arise from an interplay

527 between the individual calcium oscillations of gap junction-coupled neurons (Bindschadler and

528 Sneyd, 2001; De Blasio et al., 2004; Liu et al., 2011). In addition to such processes, irregular

529 magnitude fluctuations in the voltage oscillation of the B63 neurons could also partly result

530 from plateau potential production in the different electrically-coupled neurons of the buccal 
531 CPG network. Presumably, because these plateaus are generated in the soma, far from the

532 intercellular junctions in the neuropile, they are not phase-coupled in the different network

533 neurons, producing only weak depolarizations in post-junctional cell partners. Nevertheless,

534 these uncoordinated depolarizations would be sufficient to participate in randomly modifying

535 the amplitude of the ongoing voltage oscillation in the B63 neurons:

\section{Propagation of pacemaker activity amongst gap junction-connected neurons}

538 It is well known that gap junction-mediated electrical coupling promotes the synchronization of 539 pacemaker neuron bursting in CPG networks (Leznik and Llinás, 2005; Marder, 1984; Nadim et

540 al., 2017; Sasaki et al., 2013; Sieling et al., 2014; Soto-Treviño et al., 2005), and is similarly

541 involved in Aplysia's buccal feeding circuit (Sieling et al., 2014). In non-neuronal tissues, gap

542 junctions have also been found to co-ordinate multicellular activity by propagating calcium

543 waves via metabolic coupling (Benninger et al., 2008; Leybaert and Sanderson, 2012; Peters et

544 al., 2007). Due to strong intracellular buffering mechanisms, calcium itself is unlikely to play a

545 role in such intercellular communication (Leybaert and Sanderson, 2012). Rather, calcium wave

546 propagation through gap junctions is most likely mediated by a diffusion of IP3 and its chain

547 activation of IP3/Ry receptors and calcium release within adjacent cells (Harootunian et al.,

548 1991; Miyazaki et al., 1992; Takeuchi et al., 2020). In addition to transfer through gap junctions,

549 calcium waves can be propagated by extracellular paracrine signaling involving calcium-induced

550 ATP release and an activation of ATP-gated membrane receptors and resultant IP3 synthesis in

551 neighboring cells (Newman and Zahs, 1997; Scemes and Giaume, 2006). 
Several lines of evidence suggest that the calcium dynamic driving membrane potential

553 oscillation and originating in the B63 neurons is also conveyed non-electrically to its gap

554 junction-coupled partners in the buccal network. First, the magnitude of B63's voltage

555 oscillation, which is presumably proportional to the intracellular calcium signal, was

556 consistently stronger than in any other network cells, such as B30, B31 and B65, despite their

557 similar membrane input resistances. Second, the voltage oscillation in B63 preceded that

558 recorded in these other cells by several seconds, which is compatible with a slower propagation

$559(\sim 70 \mu \mathrm{m} / \mathrm{s})$ of the underlying calcium oscillatory signal by a metabolic process rather than by

560 direct electrical transmission of the voltage oscillation itself (Benninger et al., 2008). Third, the

561 intracellular injection of the IP3 receptor antagonist heparin into B63, but not into B31,

562 suppressed the voltage oscillation in both neurons, thus indicating that its origin and

563 intercellular propagation is selectively dependent on IP3 signaling in B63. These findings also

564 argue against the possibility that the oscillation occurring throughout the buccal CPG circuit is a

565 network property that emerges from electrical coupling between equivalently-active neurons,

566 but rather, further underline the crucial pacemaker role played by B63 in buccal network

567 operation. In contrast to all other identified circuit cells, this neuron pair are the only elements

568 necessary and sufficient for triggering buccal motor pattern expression and resultant food-

569 seeking movement (Hurwitz et al., 1997; Nargeot et al., 2009). Moreover, this essential leading

570 role persists after appetitive operant conditioning-when the network's junctional conductances

571 are strengthened and the transition from irregular to rhythmic BMP genesis occurs (Nargeot et

572 al., 2009; Nargeot and Simmers, 2012). 
In conclusion, without excluding the involvement of other cellular mechanisms, our

574 study shows that in the absence of extrinsic stimulation, the CPG network output for Aplysia's

575 food-seeking behavior can arise from a combination of spontaneous intracellular calcium

576 dynamics in two decision neurons and IP3-dependent circuit-wide metabolic propagation.

577 Although autonomously bursting neurons may employ intracellular stores as a source of

578 calcium (Kadiri et al., 2011; Levy, 1992; Scholz et al., 1988), in all cases, the mobilization of store

579 calcium, by interacting with calcium-activated membrane channels, is thought to regulate the

580 voltage dynamics of ongoing bursting behavior. However, other than theoretical evidence

581 (Chay, 1996a, 1996b), a spontaneous and rhythmic organelle-derived calcium dynamic serving

582 as a primary oscillator mechanism for actually driving neuronal bursting has not been previously

583 reported. Moreover, we believe that our findings provide the first example of the involvement

584 of such a rhythmogenic mechanism in the highly variable expression of a motivated behavior.

585 Experiments are now required to determine whether B63's intracellular calcium handling is

586 regulated by associative learning when hungry Aplysia switches its impulsive and irregular food-

587 seeking movements to a rhythmic compulsive-like act as found in more complex organisms. 
590 Materials and Methods

591 Animals

592 Adult Aplysia californica (purchased from the University of Florida, Florida), and A. fasciata 593 (caught locally in the Bassin d'Arcachon, France) were used in the experiments. Consistent with 594 previous studies (Katzoff et al., 2002; Sieling et al., 2014), no inter-species differences in either

595 behavioral or neuronal characteristics were found. Animals were housed in tanks containing 596 fresh aerated sea water $\left(\sim 15^{\circ} \mathrm{C}\right)$ and were fed ad libitum with seaweed (Ulva lactuca obtained 597 from the Station Biologique at Roscoff, France).

\section{Isolated nervous preparation}

600 Animals were anesthetized with $50 \mathrm{ml}$ isotonic $\mathrm{MgCl}_{2}$ solution (in $\mathrm{mM}: 360 \mathrm{MgCl}_{2}, 10 \mathrm{HEPES}$

601 adjusted to $\mathrm{pH}$ 7.5) injected into the hemocoel. The bilateral buccal ganglia and their peripheral 602 nerves were dissected from the animal and pinned out in a Sylgard-lined Petri dish containing a 603 standard artificial sea water solution (ASW, in mM: $450 \mathrm{NaCl}, 10 \mathrm{KCl}, 30 \mathrm{MgCl}_{2}, 20 \mathrm{MgSO}_{4}, 10$

$604 \mathrm{CaCl}_{2}, 10 \mathrm{HEPES}$ with the $\mathrm{pH}$ adjusted to 7.5). The ganglia were desheathed to expose the 605 neuronal somata and the preparations were continuously superfused with ASW at $15^{\circ} \mathrm{C}$.

\section{In vitro electrophysiology}

608 Spontaneous buccal motor output patterns were monitored by wire electrodes placed against 609 appropriate motor nerves and insulated from the bath with petroleum jelly (Vaseline). The 12 
610 (I2 n.), 2,1 (n. 2,1) and radular ( $\mathrm{R}$ n.) nerves were used to monitor radular protraction,

611 retraction and closure activity, respectively (Nargeot et al., 1997). The motor pattern-initiating

612 interneurons B63 and B30, and the motoneurons B31/B32 (protraction) and B8 (closure) were

613 recorded and identified according to previously reported criteria (Church and Lloyd, 1991;

614 Hurwitz et al., 1997; Jelescu et al., 2013; Jing et al., 2004; Susswein and Byrne, 1988). These

615 neurons were impaled with sharp glass microelectrodes with a tip resistance of 20-30 $\mathrm{M} \Omega$ and

616 filled with a $\mathrm{KCH}_{3} \mathrm{CO}_{2}$ solution $(2 \mathrm{M})$. In the two-electrode current-clamp condition, two

617 intrasomatic electrodes were inserted in each neuron, with one electrode used for current

618 injection and the other for membrane potential recording via an Axoclamp-2B amplifier

619 (Molecular Devices, Palo Alto, CA). Intracellular and extracellular signals were digitalized and

620 acquired at $5 \mathrm{kHz}$ with a CED interface (CED 1401, Cambridge Electronic Design, UK) with Spike

6212 software (Cambridge Electronic Design, UK).

622

\section{Modified saline and pharmacology}

624 Blockade of chemical synaptic transmission was performed with bath perfusion of a modified

625 ASW that contained cobalt, a calcium channel blocker $\left(\mathrm{CoCl}_{2}, 10 \mathrm{mM}\right)$, and a lowered

626 concentration of calcium $\left(\mathrm{CaCl}_{2}, 3 \mathrm{mM}\right.$ ) (Alkon and Grossman, 1978). Neither this decrease in

$627 \mathrm{Ca}^{2+}$ concentration alone, nor the presence of the $\mathrm{CoCl}_{2}$ alone was found sufficient to block the

628 chemical synapses. This 'Low Ca+Co' saline contained (in mM): $446 \mathrm{NaCl}, 10 \mathrm{KCl}, 30 \mathrm{MgCl}, 20$

$629 \mathrm{MgSO}_{4}, 3 \mathrm{CaCl}_{2}, 10 \mathrm{CoCl}_{2}, 10 \mathrm{HEPES}$ with the $\mathrm{NaCl}$ concentration adjusted to the same

630 osmolarity as ASW. Synaptic blockade was indicated by the suppression of chemical excitatory

631 post-synaptic potentials produced by B63 in the contralateral B31 neuron (Hurwitz et al., 1997). 
632 Data reported here under the Low $\mathrm{Ca}+\mathrm{Co}$ saline condition were acquired after 20 min perfusion

633 to allow for a complete synaptic blockade and the recovery of recorded neurons' resting

634 membrane potential to at least $-50 \mathrm{mV}$.

635 The sodium- or calcium-free solutions used in several experiments derived from

636 modifications to the Low $\mathrm{Ca}+\mathrm{Co}$ saline. In the $\mathrm{Na}^{+}$-free saline, sodium was totally substituted by

637 choline (in mM: $446 \mathrm{C}_{5} \mathrm{H}_{14} \mathrm{NO} . \mathrm{Cl}, 10 \mathrm{KCl}, 30 \mathrm{MgCl}_{2}, 20 \mathrm{MgSO}_{4}, 3 \mathrm{CaCl}_{2}, 10 \mathrm{CoCl}_{2}, 10 \mathrm{HEPES}$ ). In

638 the $\mathrm{Ca}^{2+}$-free saline, no calcium was present and a calcium chelator, Ethylene glycol-bis (2-

639 aminoethylether)- $N, \mathrm{~N}, \mathrm{~N}^{\prime}, \mathrm{N}^{\prime}$-tetraacetic acid (EGTA) was added to the solution (in mM: 450

$640 \mathrm{NaCl}, 10 \mathrm{KCl}, 30 \mathrm{MgCl}_{2}, 20 \mathrm{MgSO}_{4}, 10 \mathrm{CoCl}_{2}, 10 \mathrm{HEPES}, 0.5 \mathrm{EGTA}$ ) (Hickey et al., 2010). The pH

641 for all solutions was adjusted to 7.5.

Tetrodotoxin (TTX, Tocris), a blocker of sodium channels in plasma membranes, was

643 diluted to $50 \mu \mathrm{M}$ in distilled water from a $0.5 \mathrm{mM}$ stock solution (Hurwitz et al., 2008).

644 Cyclopianozic acid (CPA, Merck-Sigma-Aldrich), a blocker of the sarco/endoplasmic reticulum

$645 \mathrm{Ca}^{2+}$-ATPase pump (SERCA) and Carbonyl cyanide 4- (trifluoromethoxy) phenylhydrazone (FCCP,

646 Merck-Sigma-Aldrich), a protonophoric uncoupler of mitochondrial oxidative phosphorylation

647 that depolarizes the mitochondrial membrane and leads to the organelle's release of calcium,

648 were diluted to $20 \mu \mathrm{M}$ in Low Ca+Co saline from stock solutions that were prepared in dimethyl

649 sulfoxide (DMSO) (Benz and McLaughlin, 1983; Geiger and Magoski, 2008; Hickey et al., 2010).

650 The maximum concentration of DMSO in the final volume reached $0.05 \%$, which in control and

651 previously reported studies did not alter the electrophysiological properties of neurons, the

652 strength of electrical synapses, or intracellular calcium concentrations (Beekharry et al., 2018). 
Heparin sodium salt solution (Tocris) at $20 \mathrm{mg} / \mathrm{ml}$, an inositol tri-phosphate (IP3)

654 receptor antagonist (Bezin et al., 2008), was pressure injected via an glass micropipette (10

$655 \mathrm{M} \Omega$ ) inserted into the cell bodies of the bilateral B63 or B31 neurons. Pressure was generated

656 by a Picospritzer 2 with 20 pulses of 15 PSI, $150 \mathrm{~ms}$, at around $0.03 \mathrm{~Hz}$. Following injection,

657 which was performed during bath perfusion of ASW, one of the 2 heparin-containing electrodes

658 was removed and replaced by a $2 \mathrm{M}$ KAcetate microelectrode for intracellular recording that

659 started 30 min after the heparin injection. In several of these experiments (2/5 with B63 and

$6602 / 4$ with B31), $2 \mathrm{mg} / \mathrm{ml}$ of fast green (Merck-Sigma-Aldrich) was added to the heparin solution

661 to verify effectiveness of the injection. No difference was found between the intracellular

662 recordings of cells injected with or without fast green.

663

664 Intracellular recording analysis

665 Variations in the membrane potential of recorded neurons were analyzed in a cycle

666 frequency/period bandwidth of 0.00195 to $0.125 \mathrm{~Hz}$ (i.e., periods of $512 \mathrm{~s}$ to $8 \mathrm{~s}$ ) by Fast Fourier

667 Transform (FFT) analysis using R language and environment (R Core Team, 2019) for statistical

668 computing. The membrane voltage recordings were initially smoothed using the Spike 2

669 'Smooth' filter with a time constant of $500 \mathrm{~ms}$ to suppress signals of frequencies higher than

670 those within the desired band-width and down-sampled at $1 \mathrm{~Hz}$ in order to decrease

671 computation time. The resulting power spectral density periodograms were then used to

672 identify oscillation periods of peak magnitude (Supplemental Figure 1). The periodograms were

673 computed from the FFT frequency spectrograms by converting the frequency band (in $\mathrm{Hz}$ ) to its

674 reciprocal, period (in secs), to facilitate discerning the temporal correspondence between these 
675 plots and the relatively slow (from secs to mins ) spontaneous membrane voltage fluctuations

676 occurring in the raw recordings. Reconstruction of the sinusoidal waveforms corresponding to

677 dominant periods and the phase-relationships between signals from neuron pairs were

678 computed from Wavelet decomposition using the R-CRAN "WaveletComp" package for the

679 built-in analysis of univariate and bivariate time series (Roesch and Schmidbauer, 2018).

680 Averaged periodograms represent means $+/-95 \%$ confidence interval (CI95\%) of the individual

681 periodograms. Phase-plane plots of membrane potential were computed by using custom-

682 written R script for intracellular recordings that were smoothed with a time constant of $500 \mathrm{~ms}$

683 and down-sampled at $10 \mathrm{~Hz}$.

685 Statistical analyses

686 Animals were randomly assigned to each experimental group, and although estimations of

687 sample sizes were not computed initially, an attempt was made to minimize the number of

688 animals sacrificed. One-sample comparisons to a theoretical value $(0 \mathrm{sec}$.) were performed

689 using the two-tailed one-sample Wilcoxon signed rank test ( $\mathrm{V}_{0}$ statistic). Within-group

690 comparisons of two datasets were carried out using the two-tailed Wilcoxon signed rank test (V

691 statistic). Between-group comparisons for more than two independent groups were conducted

692 using the two-tailed Kruskal-Wallis test (H statistic) followed by the post-hoc multiple

693 comparisons Conover's test (q statistic). The application of these non-parametric statistical

694 tests to small datasets was justified by the failure to satisfy assumptions of normality and

695 homoscedasticity with high statistical powers. Statistical analyses were performed using the R-

696 CRAN "Base" and "PMCMRplus" packages (Pohlert, 2019). Similar results were obtained with 
analyses performed both with and without outlier values, and all statistics reported in the text

and figures were computed without data removal. Differences were considered significant for $p$

< 0.05. Box-plot illustrations represent median values (horizontal lines) along with the first and

700 third quartiles (boxes) in datasets.

701

702

\section{Acknowledgements:}

703 This research was supported by grants ANImE ANR-13-BV5-0014-01 (ANImE, R.N.), ANR-10-

704 Idex-03-02 (A.B.), and a doctoral studentship (L.P.) from the French 'Ministère de

705 l'Enseignement Supérieur et de la Recherche'.

706

707

\section{Competing interests:}

The authors declare that no competing interests exist.

\section{References}

Adams WB, Benson JA. 1985. The generation and modulation of endogenous rhythmicity in the aplysia bursting pacemaker neurone R15. Progress in Biophysics and Molecular Biology 46:1-49. doi:10.1016/0079-6107(85)90011-2

Alkon DL, Grossman Y. 1978. Evidence for nonsynaptic neuronal interaction. J Neurophysiol 41:640-653. doi:10.1152/jn.1978.41.3.640

Baker SA, Drumm BT, Saur D, Hennig GW, Ward SM, Sanders KM. 2016. Spontaneous Ca(2+) transients in interstitial cells of Cajal located within the deep muscular plexus of the murine small intestine. J Physiol 594:3317-3338. doi:10.1113/JP271699

Bal T, Nagy F, Moulins M. 1988. The pyloric central pattern generator in Crustacea: a set of conditional neuronal oscillators. Journal of Comparative Physiology A 163:715-727. doi:10.1007/BF00604049

Balleine BW. 2019. The Meaning of Behavior: Discriminating Reflex and Volition in the Brain. Neuron 104:47-62. doi:10.1016/j.neuron.2019.09.024

Balleine BW, Dezfouli A. 2019. Hierarchical Action Control: Adaptive Collaboration Between Actions and Habits. Front Psychol 10:2735. doi:10.3389/fpsyg.2019.02735 
Beekharry CC, Gu Y, Magoski NS. 2018. Protein kinase C enhances electrical synaptic transmission by acting on junctional and postsynaptic Ca2+ Currents. J Neurosci 38:2796-2808. doi:10.1523/JNEUROSCI.2619-17.2018

Benninger RKP, Zhang M, Head WS, Satin LS, Piston DW. 2008. Gap junction coupling and calcium waves in the pancreatic islet. Biophys J 95:5048-5061. doi:10.1529/biophysj.108.140863

Benz R, McLaughlin S. 1983. The molecular mechanism of action of the proton ionophore FCCP (carbonylcyanide p-trifluoromethoxyphenylhydrazone). Biophys J 41:381-398. doi:10.1016/S0006-3495(83)84449-X

Berridge KC. 2019. Affective valence in the brain: modules or modes? Nat Rev Neurosci 20:225-234. doi:10.1038/s41583-019-0122-8

Berridge KC. 2004. Motivation concepts in behavioral neuroscience. Physiol Behav 81:179-209. doi:10.1016/j.physbeh.2004.02.004

Bezin S, Charpentier G, Lee HC, Baux G, Fossier P, Cancela J-M. 2008. Regulation of nuclear $\mathrm{Ca} 2+$ signaling by translocation of the $\mathrm{Ca} 2+$ messenger synthesizing enzyme ADPribosyl cyclase during neuronal depolarization. J Biol Chem 283:27859-27870. doi:10.1074/jbc.M804701200

Bindschadler M, Sneyd J. 2001. A bifurcation analysis of two coupled calcium oscillators. Chaos 11:237-246. doi:10.1063/1.1342161

Brembs B, Lorenzetti FD, Reyes FD, Baxter DA, Byrne JH. 2002. Operant reward learning in Aplysia: neuronal correlates and mechanisms. Science 296:1706-1709. doi:10.1126/science.1069434

Brocard F, Shevtsova NA, Bouhadfane M, Tazerart S, Heinemann U, Rybak IA, Vinay L. 2013. Activity-dependent changes in extracellular $\mathrm{Ca} 2+$ and $\mathrm{K}+$ reveal pacemakers in the spinal locomotor-related network. Neuron 77:1047-1054. doi:10.1016/j.neuron.2013.01.026

Butera RJ, Clark JW, Byrne JH. 1996. Dissection and reduction of a modeled bursting neuron. $J$ Comput Neurosci 3:199-223. doi:10.1007/BF00161132

Calabrese RL. 1995. Oscillation in motor pattern-generating networks. Curr Opin Neurobiol 5:816-823. doi:10.1016/0959-4388(95)80111-1

Canavier CC, Clark JW, Byrne JH. 1991. Simulation of the bursting activity of neuron R15 in Aplysia: role of ionic currents, calcium balance, and modulatory transmitters. $J$ Neurophysiol 66:2107-2124. doi:10.1152/jn.1991.66.6.2107

Carroll MS, Ramirez J-M. 2013. Cycle-by-cycle assembly of respiratory network activity is dynamic and stochastic. J Neurophysiol 109:296-305. doi:10.1152/jn.00830.2011

Chay TR. 1996a. Electrical bursting and luminal calcium oscillation in excitable cell models. Biol Cybern 75:419-431. doi:10.1007/s004220050307

Chay TR. 1996b. Modeling slowly bursting neurons via calcium store and voltage-independent calcium current. Neural Comput 8:951-978. doi:10.1162/neco.1996.8.5.951

Chevalier M, Toporikova N, Simmers J, Thoby-Brisson M. 2016. Development of pacemaker properties and rhythmogenic mechanisms in the mouse embryonic respiratory network. Elife 5. doi:10.7554/eLife.16125

Church PJ, Lloyd PE. 1991. Expression of diverse neuropeptide cotransmitters by identified motor neurons in Aplysia. J Neurosci 11:618-625.

Costa RM, Baxter DA, Byrne JH. 2020. Computational model of the distributed representation of operant reward memory: combinatoric engagement of intrinsic and synaptic plasticity mechanisms. Learn Mem 27:236-249. doi:10.1101/lm.051367.120 
Cullins MJ, Gill JP, McManus JM, Lu H, Shaw KM, Chiel HJ. 2015. Sensory Feedback Reduces Individuality by Increasing Variability within Subjects. Curr Biol 25:2672-2676. doi:10.1016/j.cub.2015.08.044

Darbon P, Tscherter A, Yvon C, Streit J. 2003. Role of the electrogenic Na/K pump in disinhibition-induced bursting in cultured spinal networks. J Neurophysiol 90:31193129. doi:10.1152/jn.00579.2003

Darshan R, Wood WE, Peters S, Leblois A, Hansel D. 2017. A canonical neural mechanism for behavioral variability. Nat Commun 8:15415. doi:10.1038/ncomms 15415

De Blasio BF, Iversen J-G, Røttingen J-A. 2004. Intercellular calcium signalling in cultured renal epithelia: a theoretical study of synchronization mode and pacemaker activity. Eur Biophys J 33:657-670. doi:10.1007/s00249-004-0409-0

Dickinson A, Balleine B. 1994. Motivational control of goal-directed action. Animal Learning \& Behavior 22:1-18.

Everitt BJ, Robbins TW. 2016. Drug Addiction: Updating Actions to Habits to Compulsions Ten Years On. Annu Rev Psychol 67:23-50. doi:10.1146/annurev-psych-122414-033457

Everitt BJ, Robbins TW. 2005. Neural systems of reinforcement for drug addiction: from actions to habits to compulsion. Nat Neurosci 8:1481-1489. doi:10.1038/nn1579

Falcke M, Huerta R, Rabinovich MI, Abarbanel HD, Elson RC, Selverston AI. 2000. Modeling observed chaotic oscillations in bursting neurons: the role of calcium dynamics and IP3. Biol Cybern 82:517-527. doi:10.1007/s004220050604

Fridlyand LE, Tamarina N, Philipson LH. 2010. Bursting and calcium oscillations in pancreatic beta-cells: specific pacemakers for specific mechanisms. Am J Physiol Endocrinol Metab 299:E517-532. doi:10.1152/ajpendo.00177.2010

Fujimoto A, Hori Y, Nagai Y, Kikuchi E, Oyama K, Suhara T, Minamimoto T. 2019. Signaling Incentive and Drive in the Primate Ventral Pallidum for Motivational Control of GoalDirected Action. J Neurosci 39:1793-1804. doi:10.1523/JNEUROSCI.2399-18.2018

Geiger JE, Magoski NS. 2008. Ca2+-induced Ca2+ release in Aplysia bag cell neurons requires interaction between mitochondrial and endoplasmic reticulum stores. J Neurophysiol 100:24-37. doi:10.1152/jn.90356.2008

Golowasch J, Bose A, Guan Y, Salloum D, Roeser A, Nadim F. 2017. A balance of outward and linear inward ionic currents is required for generation of slow-wave oscillations. $J$ Neurophysiol 118:1092-1104. doi:10.1152/jn.00240.2017

Grillner S, El Manira A. 2020. Current Principles of Motor Control, with Special Reference to Vertebrate Locomotion. Physiol Rev 100:271-320. doi:10.1152/physrev.00015.2019

Groten CJ, Rebane JT, Blohm G, Magoski NS. 2013. Separate Ca2+ sources are buffered by distinct $\mathrm{Ca} 2+$ handling systems in aplysia neuroendocrine cells. J Neurosci 33:64766491. doi:10.1523/JNEUROSCI.6384-11.2013

Gu X, Olson EC, Spitzer NC. 1994. Spontaneous neuronal calcium spikes and waves during early differentiation. $J$ Neurosci 14:6325-6335. doi:10.1523/JNEUROSCI.14-1106325.1994

Haberichter T, Marhl M, Heinrich R. 2001. Birhythmicity, trirhythmicity and chaos in bursting calcium oscillations. Biophys Chem 90:17-30. doi:10.1016/s0301-4622(01)00127-2

Hajnóczky G, Robb-Gaspers LD, Seitz MB, Thomas AP. 1995. Decoding of cytosolic calcium oscillations in the mitochondria. Cell 82:415-424. doi:10.1016/0092-8674(95)90430-1 
Harootunian AT, Kao JP, Paranjape S, Tsien RY. 1991. Generation of calcium oscillations in fibroblasts by positive feedback between calcium and IP3. Science 251:75-78. doi:10.1126/science.1986413

Harris-Warrick RM. 2002. Voltage-sensitive ion channels in rhythmic motor systems. Curr Opin Neurobiol 12:646-651. doi:10.1016/s0959-4388(02)00377-x

Harris-Warrick RM, Flamm RE. 1987. Multiple mechanisms of bursting in a conditional bursting neuron. J Neurosci 7:2113-2128.

Hickey CM, Geiger JE, Groten CJ, Magoski NS. 2010. Mitochondrial Ca2+ activates a cation current in Aplysia bag cell neurons. J Neurophysiol 103:1543-1556. doi:10.1152/jn.01121.2009

Hurwitz I, Kupfermann I, Susswein AJ. 1997. Different roles of neurons B63 and B34 that are active during the protraction phase of buccal motor programs in Aplysia californica. $J$ Neurophysiol 78:1305-1319. doi:10.1152/jn.1997.78.3.1305

Hurwitz I, Ophir A, Korngreen A, Koester J, Susswein AJ. 2008. Currents contributing to decision making in neurons B31/B32 of Aplysia. J Neurophysiol 99:814-830. doi:10.1152/jn.00972.2007

Jelescu IO, Nargeot R, Le Bihan D, Ciobanu L. 2013. Highlighting manganese dynamics in the nervous system of Aplysia californica using MEMRI at ultra-high field. Neuroimage 76:264-271. doi:10.1016/j.neuroimage.2013.03.022

Jing J, Cropper EC, Hurwitz I, Weiss KR. 2004. The construction of movement with behaviorspecific and behavior-independent modules. J Neurosci 24:6315-6325. doi:10.1523/JNEUROSCI.0965-04.2004

Johnson SW, Seutin V, North RA. 1992. Burst firing in dopamine neurons induced by N-methylD-aspartate: role of electrogenic sodium pump. Science 258:665-667. doi:10.1126/science.1329209

Kadiri LR, Kwan AC, Webb WW, Harris-Warrick RM. 2011. Dopamine-induced oscillations of the pyloric pacemaker neuron rely on release of calcium from intracellular stores. $J$ Neurophysiol 106:1288-1298. doi:10.1152/jn.00456.2011

Katzoff A, Ben-Gedalya T, Susswein AJ. 2002. Nitric oxide is necessary for multiple memory processes after learning that a food is inedible in Aplysia. J Neurosci 22:9581-9594.

Koshiya N, Smith JC. 1999. Neuronal pacemaker for breathing visualized in vitro. Nature 400:360-363. doi:10.1038/22540

Kramer RH, Zucker RS. 1985. Calcium-dependent inward current in Aplysia bursting pacemaker neurones. J Physiol 362:107-130. doi:10.1113/jphysiol.1985.sp015666

Kueh D, Barnett WH, Cymbalyuk GS, Calabrese RL. 2016. $\mathrm{Na}(+) / \mathrm{K}(+)$ pump interacts with the h-current to control bursting activity in central pattern generator neurons of leeches. Elife 5. doi:10.7554/eLife.19322

Kupfermann I. 1974. Feeding behavior in Aplysia: a simple system for the study of motivation. Behav Biol 10:1-26. doi:10.1016/s0091-6773(74)91644-7

Levy S. 1992. Effect of intracellular injection of inositol trisphosphate on cytosolic calcium and membrane currents in Aplysia neurons. J Neurosci 12:2120-2129. doi:10.1523/JNEUROSCI.12-06-02120.1992

Leybaert L, Sanderson MJ. 2012. Intercellular Ca(2+) waves: mechanisms and function. Physiol Rev 92:1359-1392. doi:10.1152/physrev.00029.2011

Leznik E, Llinás R. 2005. Role of gap junctions in synchronized neuronal oscillations in the inferior olive. J Neurophysiol 94:2447-2456. doi:10.1152/jn.00353.2005 
862

863

864

865

866

867

868

869

870

871

872

873

874

875

876

877

878

879

880

881

882

883

884

885

886

887

888

889

890

891

892

893

894

895

896

897

898

899

900

901

902

903

904

905

906

Liu P, Chen B, Wang Z-W. 2011. Gap junctions synchronize action potentials and Ca2+ transients in Caenorhabditis elegans body wall muscle. J Biol Chem 286:44285-44293. doi:10.1074/jbc.M111.292078

Liu Z, Golowasch J, Marder E, Abbott LF. 1998. A model neuron with activity-dependent conductances regulated by multiple calcium sensors. J Neurosci 18:2309-2320.

Lyttle DN, Gill JP, Shaw KM, Thomas PJ, Chiel HJ. 2017. Robustness, flexibility, and sensitivity in a multifunctional motor control model. Biol Cybern 111:25-47. doi:10.1007/s00422-016-0704-8

Marder E. 1984. Roles for electrical coupling in neural circuits as revealed by selective neuronal deletions. J Exp Biol 112:147-167.

Marder E, Goeritz ML, Otopalik AG. 2015. Robust circuit rhythms in small circuits arise from variable circuit components and mechanisms. Curr Opin Neurobiol 31:156-163. doi:10.1016/j.conb.2014.10.012

Mathieu PA, Roberge FA. 1971. Characteristics of pacemaker oscillations in Aplysia neurons. Can J Physiol Pharmacol 49:787-795. doi:10.1139/y71-108

McManus JM, Chiel HJ, Susswein AJ. 2019. Successful and unsuccessful attempts to swallow in a reduced Aplysia preparation regulate feeding responses and produce memory at different neural sites. Learn Mem 26:151-165. doi:10.1101/lm.048983.118

Melanson A, Mejias JF, Jun JJ, Maler L, Longtin A. 2017. Nonstationary Stochastic Dynamics Underlie Spontaneous Transitions between Active and Inactive Behavioral States. eNeuro 4. doi:10.1523/ENEURO.0355-16.2017

Miller JP, Selverston AI. 1982. Mechanisms underlying pattern generation in lobster stomatogastric ganglion as determined by selective inactivation of identified neurons. II. Oscillatory properties of pyloric neurons. J Neurophysiol 48:1378-1391. doi:10.1152/jn.1982.48.6.1378

Miyazaki S, Yuzaki M, Nakada K, Shirakawa H, Nakanishi S, Nakade S, Mikoshiba K. 1992. Block of $\mathrm{Ca} 2+$ wave and $\mathrm{Ca} 2+$ oscillation by antibody to the inositol 1,4,5-trisphosphate receptor in fertilized hamster eggs. Science 257:251-255. doi:10.1126/science. 1321497

Nadim F, Li X, Gray M, Golowasch J. 2017. Chapter 4 - The Role of Electrical Coupling in Rhythm Generation in Small Networks In: Jing J, editor. Network Functions and Plasticity. Academic Press. pp. 51-78. doi:10.1016/B978-0-12-803471-2.00004-7

Nargeot R, Baxter DA, Byrne JH. 1997. Contingent-dependent enhancement of rhythmic motor patterns: an in vitro analog of operant conditioning. J Neurosci 17:8093-8105.

Nargeot R, Le Bon-Jego M, Simmers J. 2009. Cellular and network mechanisms of operant learning-induced compulsive behavior in Aplysia. Curr Biol 19:975-984. doi:10.1016/j.cub.2009.05.030

Nargeot R, Petrissans C, Simmers J. 2007. Behavioral and in vitro correlates of compulsive-like food seeking induced by operant conditioning in Aplysia. J Neurosci 27:8059-8070. doi:10.1523/JNEUROSCI.1950-07.2007

Nargeot R, Simmers J. 2012. Functional organization and adaptability of a decision-making network in aplysia. Front Neurosci 6:113. doi:10.3389/fnins.2012.00113

Newman EA, Zahs KR. 1997. Calcium waves in retinal glial cells. Science 275:844-847. doi:10.1126/science.275.5301.844

Pearson KG. 2000. Neural adaptation in the generation of rhythmic behavior. Annu Rev Physiol 62:723-753. doi:10.1146/annurev.physiol.62.1.723 
Peña F, Parkis MA, Tryba AK, Ramirez J-M. 2004. Differential Contribution of Pacemaker Properties to the Generation of Respiratory Rhythms during Normoxia and Hypoxia. Neuron 43:105-117. doi:10.1016/j.neuron.2004.06.023

Peters MA, Teramoto T, White JQ, Iwasaki K, Jorgensen EM. 2007. A calcium wave mediated by gap junctions coordinates a rhythmic behavior in C. elegans. Curr Biol 17:1601-1608. doi:10.1016/j.cub.2007.08.031

Pohlert T. 2019. PMCMRplus: Calculate Pairwise Multiple Comparisons of Mean Rank Sums Extended.

R Core Team. 2019. R: a language and environment for statistical computing. Vienne, Austria.

Roesch A, Schmidbauer H. 2018. WaveletComp: Computational Wavelet Analysis.

Sasaki K, Cropper EC, Weiss KR, Jing J. 2013. Functional differentiation of a population of electrically coupled heterogeneous elements in a microcircuit. $J$ Neurosci 33:93-105. doi:10.1523/JNEUROSCI.3841-12.2013

Scemes E, Giaume C. 2006. Astrocyte calcium waves: what they are and what they do. Glia 54:716-725. doi:10.1002/glia.20374

Scholz KP, Cleary LJ, Byrne JH. 1988. Inositol 1,4,5-trisphosphate alters bursting pacemaker activity in Aplysia neurons: voltage-clamp analysis of effects on calcium currents. Journal of Neurophysiology 60:86-104. doi:10.1152/jn.1988.60.1.86

Selverston AI. 2010. Invertebrate central pattern generator circuits. Philos Trans $R$ Soc Lond B Biol Sci 365:2329-2345. doi:10.1098/rstb.2009.0270

Sieling F, Bédécarrats A, Simmers J, Prinz AA, Nargeot R. 2014. Differential roles of nonsynaptic and synaptic plasticity in operant reward learning-induced compulsive behavior. Curr Biol 24:941-950. doi:10.1016/j.cub.2014.03.004

Sims DW, Humphries NE, Hu N, Medan V, Berni J. 2019. Optimal searching behaviour generated intrinsically by the central pattern generator for locomotion. Elife $\mathbf{8}$. doi:10.7554/eLife.50316

Soto-Treviño C, Rabbah P, Marder E, Nadim F. 2005. Computational model of electrically coupled, intrinsically distinct pacemaker neurons. J Neurophysiol 94:590-604. doi:10.1152/jn.00013.2005

Steuer I, Guertin PA. 2019. Central pattern generators in the brainstem and spinal cord: an overview of basic principles, similarities and differences. Rev Neurosci 30:107-164. doi:10.1515/revneuro-2017-0102

Susswein AJ, Byrne JH. 1988. Identification and characterization of neurons initiating patterned neural activity in the buccal ganglia of Aplysia. J Neurosci 8:2049-2061.

Susswein AJ, Hurwitz I, Thorne R, Byrne JH, Baxter DA. 2002. Mechanisms underlying fictive feeding in aplysia: coupling between a large neuron with plateau potentials activity and a spiking neuron. J Neurophysiol 87:2307-2323. doi:10.1152/jn.2002.87.5.2307

Takeuchi Y, Narumi R, Akiyama R, Vitiello E, Shirai T, Tanimura N, Kuromiya K, Ishikawa S, Kajita M, Tada M, Haraoka Y, Akieda Y, Ishitani T, Fujioka Y, Ohba Y, Yamada S, Hosokawa Y, Toyama Y, Matsui T, Fujita Y. 2020. Calcium Wave Promotes Cell Extrusion. Current Biology 30:670-681.e6. doi:10.1016/j.cub.2019.11.089

Tam S, Hurwitz I, Chiel HJ, Susswein AJ. 2020. Multiple Local Synaptic Modifications at Specific Sensorimotor Connections after Learning Are Associated with Behavioral Adaptations That Are Components of a Global Response Change. J Neurosci 40:43634371. doi:10.1523/JNEUROSCI.2647-19.2020 
van Helden DF, Imtiaz MS, Nurgaliyeva K, von der Weid P, Dosen PJ. 2000. Role of calcium stores and membrane voltage in the generation of slow wave action potentials in guineapig gastric pylorus. J Physiol 524 Pt 1:245-265. doi:10.1111/j.1469-7793.2000.00245.x $\mathrm{Ca} 2+$ oscillations drive sinoatrial nodal cell pacemaker function to make the heart tick. Ann N Y Acad Sci 1047:138-156. doi:10.1196/annals.1341.013

Wacquier B, Combettes L, Van Nhieu GT, Dupont G. 2016. Interplay Between Intracellular Ca 2+ Oscillations and Ca 2+ -stimulated Mitochondrial Metabolism. Scientific Reports 6:19316. doi:10.1038/srep19316

Wacquier B, Voorsluijs V, Combettes L, Dupont G. 2019. Coding and decoding of oscillatory Ca2+ signals. Seminars in Cell \& Developmental Biology, SI: Calcium signalling 94:1119. doi:10.1016/j.semcdb.2019.01.008

Wimmer K, Compte A, Roxin A, Peixoto D, Renart A, de la Rocha J. 2015. Sensory integration dynamics in a hierarchical network explains choice probabilities in cortical area MT. Nat Commun 6:6177. doi:10.1038/ncomms7177

$\mathrm{Yu}$ X, Byrne JH, Baxter DA. 2004. Modeling interactions between electrical activity and secondmessenger cascades in Aplysia neuron R15. J Neurophysiol 91:2297-2311. doi:10.1152/jn.00787.2003

Zhang G, Yu K, Wang T, Chen T-T, Yuan W-D, Yang F, Le Z-W, Guo S-Q, Xue Y-Y, Chen SA, Yang Z, Liu F, Cropper EC, Weiss KR, Jing J. 2020. Synaptic mechanisms for motor variability in a feedforward network. Sci Adv 6. doi:10.1126/sciadv.aba4856

Zhou Y, Lv M, Li T, Zhang T, Duncan R, Wang L, Lu XL. 2019. Spontaneous calcium signaling of cartilage cells: from spatiotemporal features to biophysical modeling. FASEB J 33:4675-4687. doi:10.1096/fj.201801460R

Zhu L, Selverston AI, Ayers J. 2016. Role of Ih in differentiating the dynamics of the gastric and pyloric neurons in the stomatogastric ganglion of the lobster, Homarus americanus. $J$ Neurophysiol 115:2434-2445. doi:10.1152/jn.00737.2015 
A
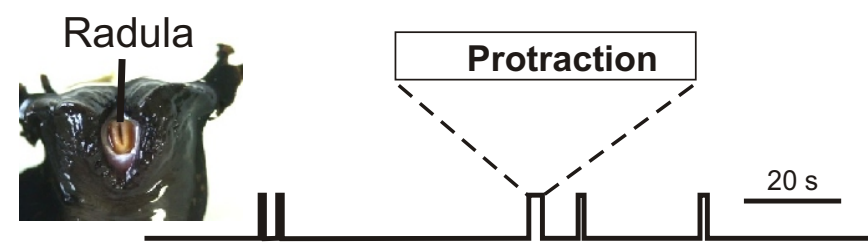

B

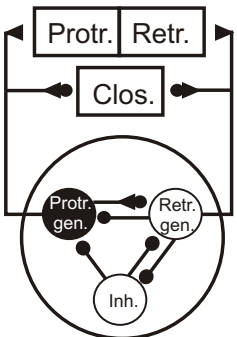

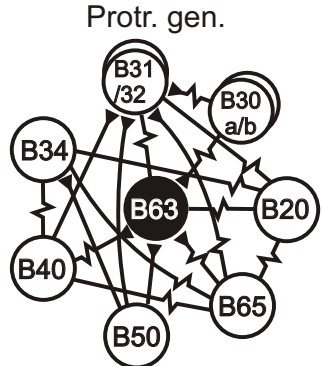

C

12 n.(Prot.)

n.2,1(Retr.)

Rn. (Clos.)

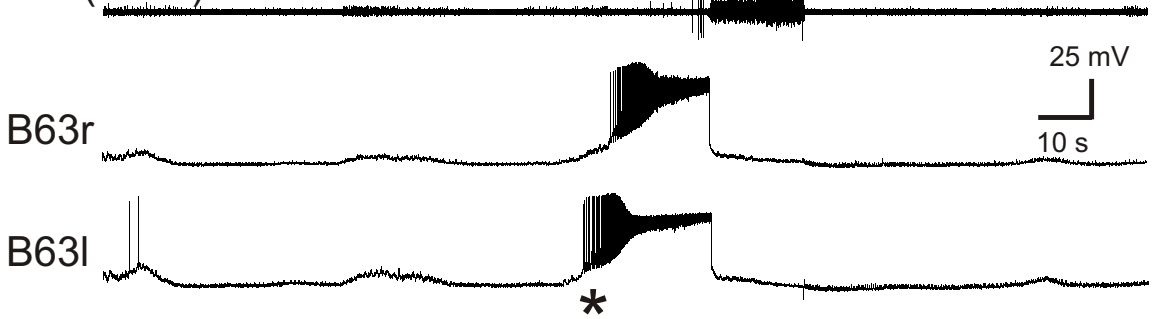

$\mathrm{D}$

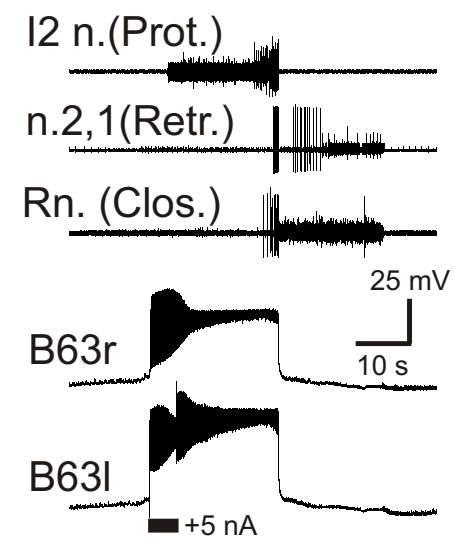

Figure 1. Aplysia's spontaneous radula biting behavior and underlying motor pattern generation.

(A) In vivo food-seeking behavior. In the absence of any external stimulation, Aplysia's radula (see head frontal view at left) spontaneously produces biting movements consisting of irregularly-timed cycles of radula protraction (upward deflection of movement monitor trace), closure and retraction (downward deflection).

(B) Schematics of the buccal CPG network that generates radula biting movements. Left: simplified diagram of the half-center network (one in each of the bilateral buccal ganglia) and its synaptic connections with protraction (Protr.), retraction (Retr.) and closure (Clos.) motoneurons (filled circles and triangles; inhibitory and excitatory connections, respectively). The network producing each bi-phasic cycle of movement is composed of three distinct and synaptically connected neuronal subsets comprising a protraction generator (Protr. gen.), a retraction generator (Retr. gen.) and a group of inhibitory neurons (Inh.). Right: detailed schematic of identified neurons belonging to the protraction generator and their synaptic interconnections (filled triangles, excitatory chemical synapses; resistance symbols, electrical synapses). Within the protraction generator, the neuron B63 (black) is necessary and sufficient to trigger the buccal motor pattern (BMP) for a radula bite cycle.

(C) Simultaneous extracellular recordings of a single BMP (top three traces) and intracellular recordings of the two bilateral and electrically-coupled B63 neurons ( $r$, right; I, left) in an isolated in vitro buccal ganglia preparation. I2n., n.2,1, Rn., are respectively the motor nerves carrying axons of protractor, retractor and closure motor neurons. The two B63 cells expressed spontaneous and coincident membrane depolarizations $\left.{ }^{*}\right)$ that initiated plateau potentials and associated impulse bursts, which in turn evoked a BMP by the buccal CPG network.

(D) Synchronous plateau potentials in the electrically-coupled B63 and a resulting BMP triggered by a brief intracellular depolarizing current pulse $(+5 \mathrm{nA})$ injected into one (left) B63 neuron. 
bioRxiv preprint doi: https://doi.org/10.1101/2021.03.30437701; this version posted March 31, 2021. The copyright holder for this preprint (which was not certified bypeer review) is the aGhor/funGer, who has granted biquxiv a license to display the preprint in perpetuity. It is made
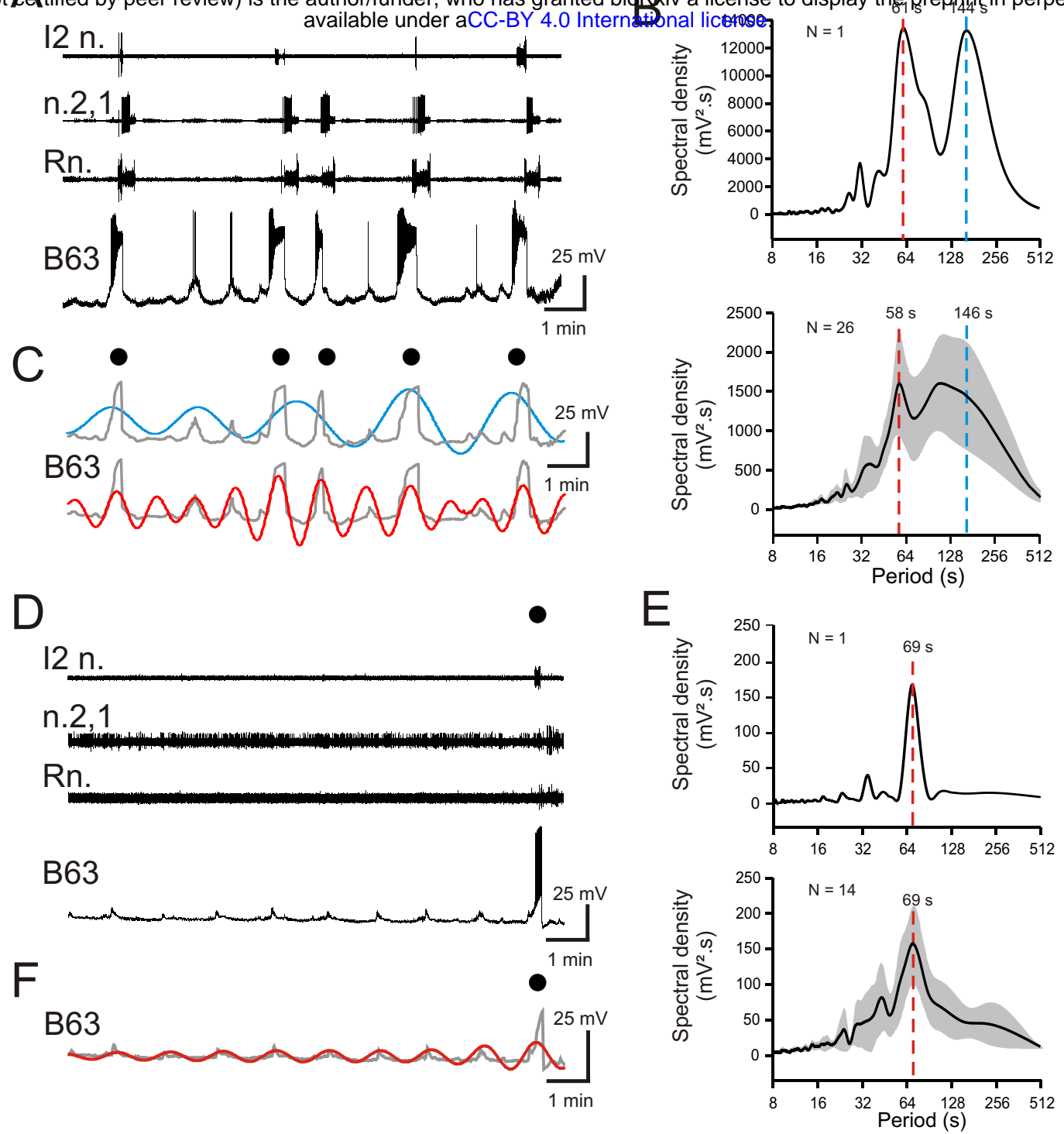

Figure 2. Periodicities in B63's spontaneous bioelectrical behavior.

(A) A 10 min recording excerpt of radula BMP genesis (black dots) in an in vitro buccal ganglion preparation showing associated spontaneous fluctuations in membrane potential of an intracellularly-recorded B63 neuron. Note that a BMP occurred only when B63 expressed prolonged burst firing driven by a plateau potential.

(B) Spectral density plot of the B63 recording illustrated in A (top) and the average power spectrum ( \pm Cl95\%) from recordings of 26 different neurons (bottom). In both cases, the essentially bimodal periodograms indicated that the variations in B63's membrane potential comprised two distinct periodicities (indicated by red and blue dashed lines), which across all 26 neurons was $58 \mathrm{~s}$ and $146 \mathrm{~s}$, respectively. For details see Supplemental Figure $1 \mathrm{~A}$.

(C) Wavelet-based reconstructions retaining the two dominant periods revealed in the individual power spectrum in B (top) and their superposition with the smoothed membrane voltage traces (gray) of the corresponding B63 neuron in A. The slower sinusoid (blue trace; period, $144 \mathrm{~s}$ ) corresponded to the cell's strongest depolarizations associated exclusively with the expression of plateau potentials and resultant BMP genesis (black dots). The faster sinusoid (red trace; period, $61 \mathrm{~s}$ ) corresponded to these supra-threshold depolarizations plus almost all remaining subthreshold depolarizations.

(D-F) Equivalent analyses of the same neurons as in A-C, but during recorded excerpts when no plateauing and BMP genesis occurred $(\mathrm{N}=14)$. The single plateau potential and BMP occurring at the end of the excerpt in $D$ is illustrated for comparison with the $B 63$ recording in $A$, but was not included in the spectral analyses of $E$ (see Supplemental Figure 1B). In the absence of plateau potentials, the cells expressed spontaneous variations in membrane potential (D) composed of a single dominant, low-amplitude oscillation (E, F). Note that smaller additional peaks in the power spectra in B, E are essentially harmonics of the major period(s). 


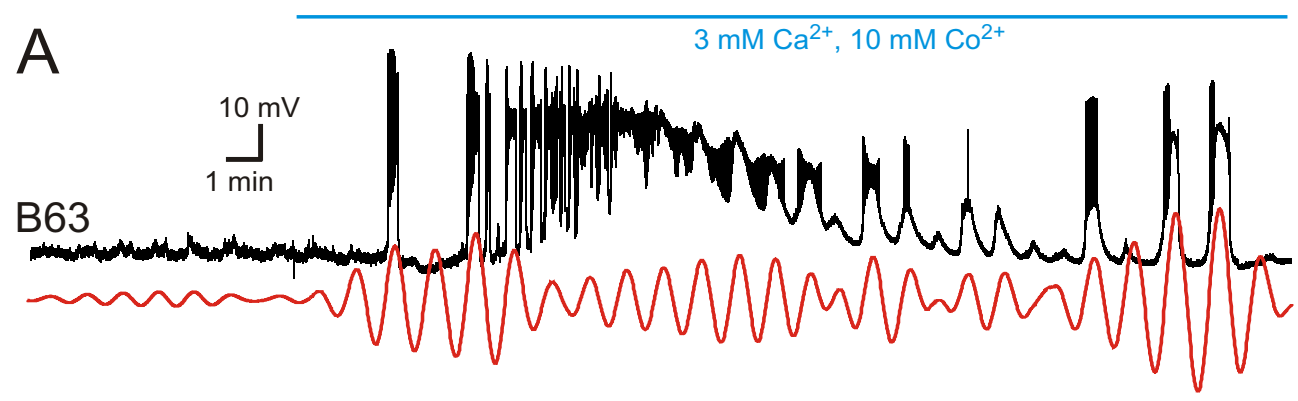

B

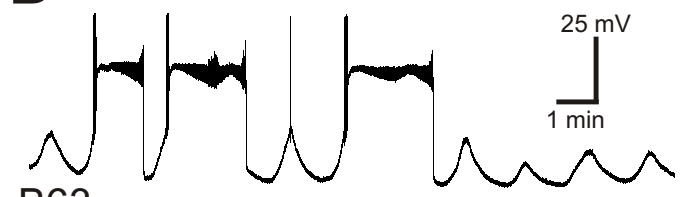

B63

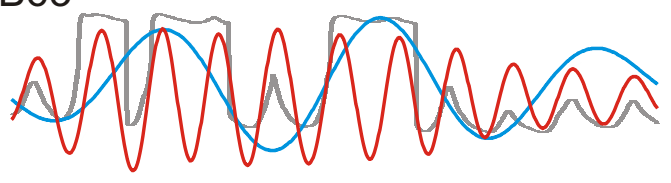

$\mathrm{D}$

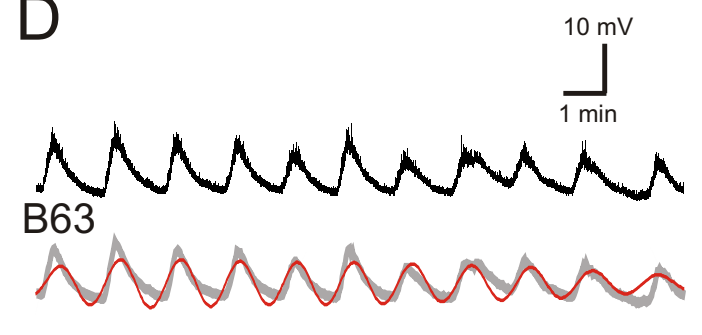

C

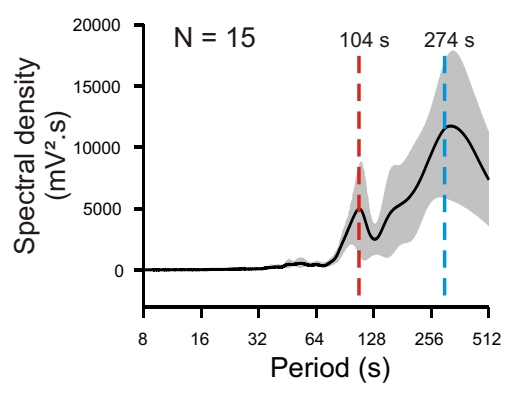

E

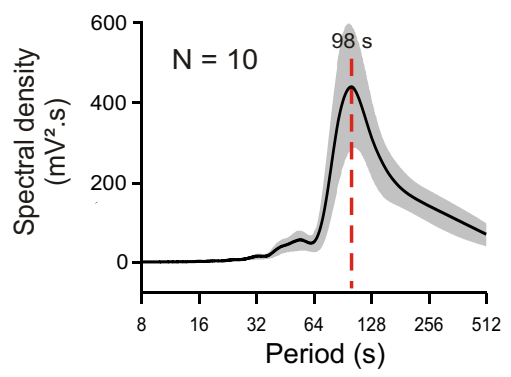

Figure 3. B63's voltage oscillations in the absence of functional chemical synapses.

(A) Membrane potential fluctuations and plateauing in a recorded B63 neuron immediately before and during onset of bath-applied Low Ca+Co saline (horizontal blue line) to block chemical synapses in the buccal CPG network. Red trace: corresponding reconstructed waveform from the peak spectral density (period range: 70$90 \mathrm{~s})$.

(B,C) A different B63 cell recorded 20 min after onset of Low Ca+Co perfusion (B, Top trace; also see Supplemental Figure 1C). The membrane potential variations decomposed into two oscillatory waveforms (B, red and blue traces) with periods of 83 and $280 \mathrm{~s}$, respectively. Gray trace: raw recording after smoothing. (C) Average power spectrum (mean period $\pm \mathrm{Cl} 195 \%$ ) from 15 neurons showing two major oscillations.

$(D, E)$ Same analysis as in B,C, but of B63 recording sequences without plateau potential generation (also see Supplemental Figure 1D). The remaining spontaneous variations in membrane potential now comprised a single oscillation ( $D$, red trace: period $85 \mathrm{~s}$ ), as also indicated by the solitary dominant period in the averaged periodogram (mean $\pm \mathrm{Cl} 95 \%$ ) from $10 \mathrm{~B} 63$ neurons $(\mathrm{E})$. 


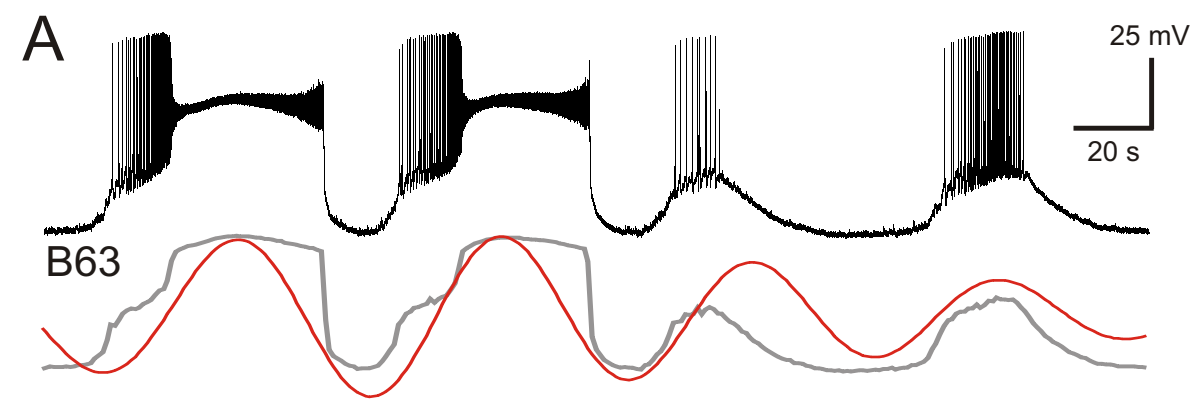

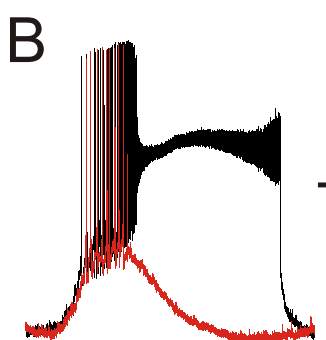

B63
C

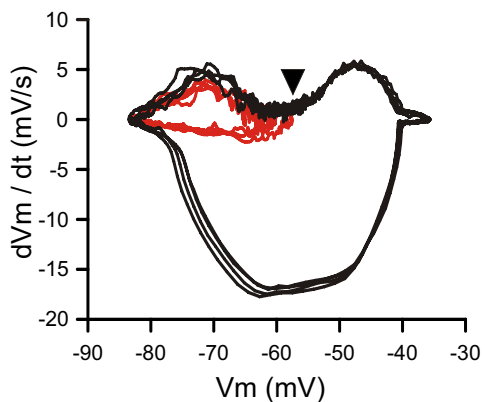

Figure 4. B63's voltage oscillation triggers plateau potentials.

(A) Intracellular recording of a B63 neuron under chemical synapse blockade during an excerpt in which each spontaneous voltage oscillation was associated (first two cycles) or not (last two cycles) with the expression of plateau potentials. Bottom traces: corresponding smoothed recording (gray trace) and reconstructed oscillation from the peak spectral density (red trace; period $64 \mathrm{~s}$ ).

(B) Left: superposition of the first oscillation cycle in A with an accompanying plateau (black trace) and the third cycle without a plateau (red trace). Right: same traces after low-pass filtering to remove action potentials.

(C) Phase-plane plot of 8 successive oscillation cycles both without (4 cycles, red), and with (4 cycles, black) plateau potential generation in the same B63 neuron as in B, C. The initial raising phases of the sub- and supra-threshold depolarizations follow identical trajectories before either a return to baseline potential or a further depolarization into a prolonged plateau. The arrowhead indicates the voltage threshold for plateau potential generation. 

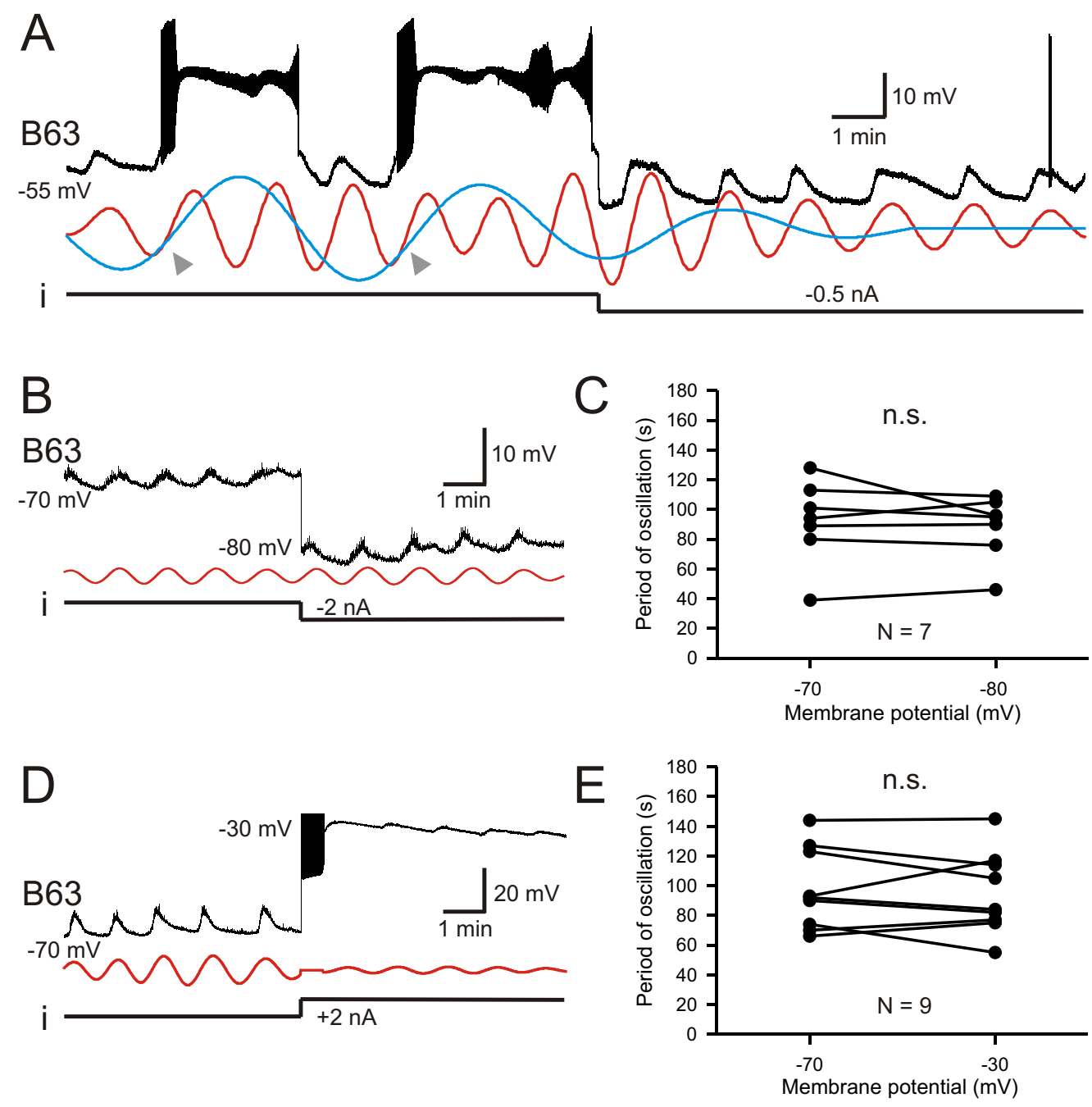

Figure 5. B63's low-amplitude oscillation does not arise from a voltage-sensitive mechanism.

(A) Under chemical synapse blockade (with Low Ca+Co saline), a B63 neuron's spontaneous plateau potentials, but not its low-amplitude voltage oscillation, is suppressed by continuous hyperpolarizing current injection (i, $-0.5 \mathrm{nA})$. Red and blue traces: superimposed reconstructed waveforms from the peak spectral densities corresponding to the presence or absence of plateau potentials. Arrowheads indicate the points of waveform intersection where plateau potentials were initiated.

(B) Low-amplitude oscillation (upper trace) in a different B63 neuron during continuous hyperpolarization with chemical synapses blocked. The cell's membrane potential was held at $-70 \mathrm{mV}$ then stepped to $-80 \mathrm{mV}$ by continuous intracellular current injection (i) with two-electrode current clamp. Red trace: reconstructed waveform from the peak spectral density (period $80 \mathrm{~s}$ ).

(C) The oscillation cycle periods of all 7 recorded neurons were not significantly (n.s.) modified by the same membrane potential manipulation $(V=16, p=0.799)$.

(D,E) Same analysis as in B,C, but with the membrane potential initially held at -70 , then depolarized to $-30 \mathrm{mV}$ with two-electrode current clamp (D). Red trace: reconstructed waveform from the peak spectral density (period: $70 \mathrm{~s}$ ). (E) No significant difference (n.s.) in oscillation period in 9 recorded neurons at these two holding potentials $(V=28, p=0.553)$. 
bioRxiv preprint doi: https://doi.org/10.1101/2021.03.30.437701; this version posted March 31, 2021. The copyright holder for this preprint (which was not certified by peer review) is the author/funder, who has granted bioRxiv a license to display the preprint in perpetuity. It is made available under aCC-BY 4.0 International license.

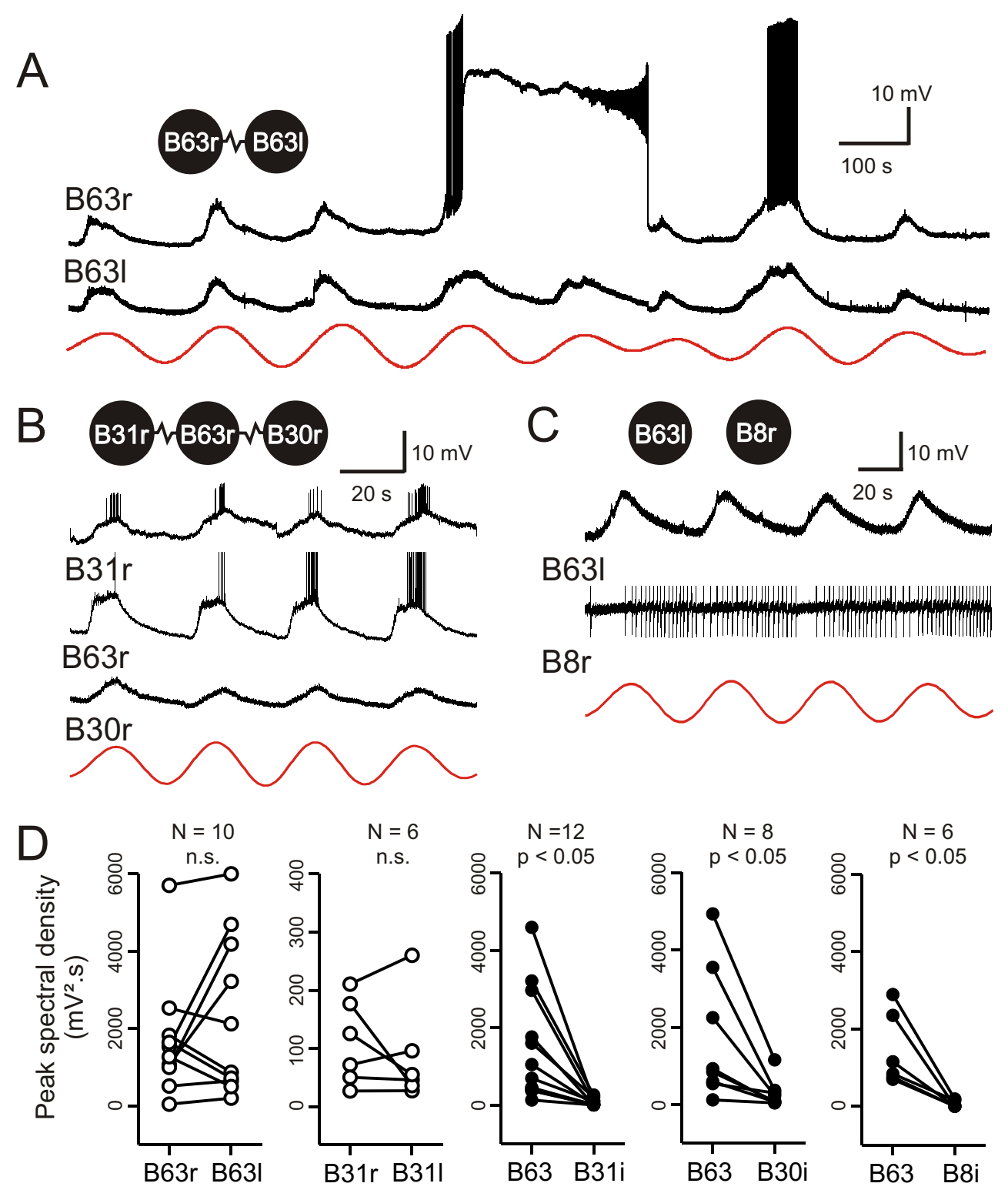

Figure 6. Low-amplitude oscillation in electrically-coupled network neurons.

$(A, B)$ Simultaneous intracellular recordings from different protraction generator neurons under chemical synapse blockade. (A) Spontaneous membrane potential oscillations in the right ( $r$ ) and left (I) electricallycoupled B63 cells (resistance symbol: electrical synapse). Note the independent expression of a plateau potential and burst firing in B63r. (B) Coordinated oscillations in a right B63 and ipsilateral, electrically-coupled B31 and B30 neurons (the action potentials in the B63 trace are truncated). Red traces in A and B: reconstructed waveforms from the peak spectral densities for B63I and B63r, respectively.

(C) Recordings from a B63 along with a non-coupled contralateral B8 motor neuron (action potentials in the B8 trace are truncated). A membrane voltage oscillation was absent in B8. Red trace: reconstructed waveform from the peak spectral density for B63.

(D) Comparison of oscillation magnitude (i.e., peak spectral amplitude) in contralateral (unfilled dots; I, left; $r$, right) and ipsilateral neurons (i, filled dots). The oscillation amplitude was not significantly different (n.s.) in bilateral homologous cells (white dots; B63r/B63I, $V=22, p=0.625$; B31r/B31l, $V=13, p=0.688$ ), but was significantly higher in $\mathrm{B} 63$ compared to heterologous neurons in the same (i, ipsilateral) ganglion (black dots: B63/B31i, $V=78, p=0.005 ; B 63 / B 30 i, V=36, p=0.008 ; B 63 / B 8 i, V=21, p=0.031$ ). 

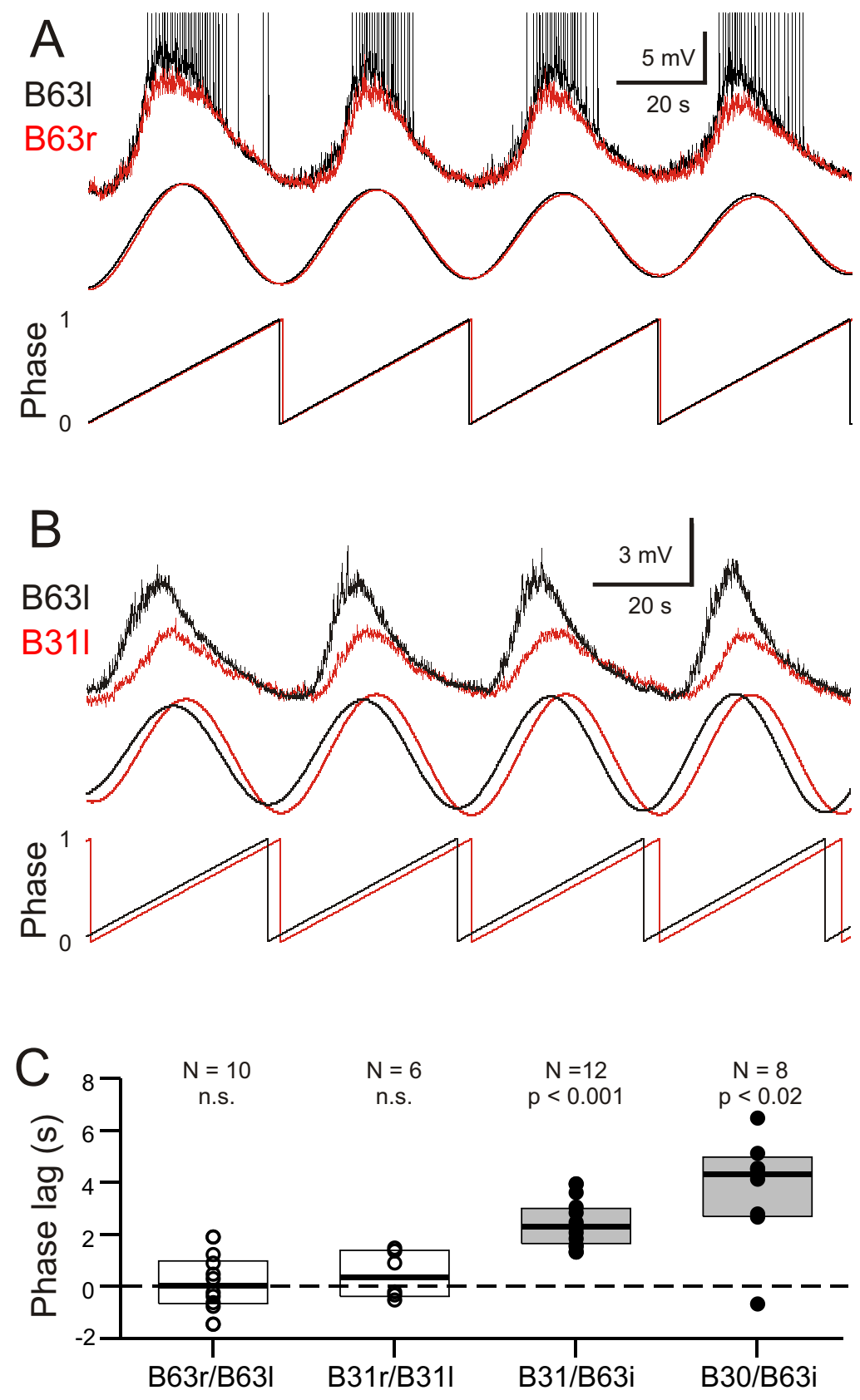

Figure 7. Phase-relationships between the oscillations of different network neurons.

(A,B) Upper traces: Superimposed phase-aligned intracellular recordings from different neuronal pairs - A), left (black) and right B63(red) ; B), left B63 (black) and left B31 (red) - under chemical synapse blockade (action potentials in B63l are truncated). Middle traces, reconstructed waveforms from the corresponding spectral periodograms after equivalence amplitude scaling. Lower traces: superimposed representations of the oscillation phases in each cell pair. No phase difference was evident between the two B63 neurons (A). In contrast, the oscillation of B63 (black) was phase-advanced relative to that of B31 (B).

(C) One-sample analyses showing that the oscillation phases in homologous bilateral neurons were not significantly (n.s.) different from zero (unfilled dots and boxes; B63r/B63I, V0 $=31, p=0.770$; B31r/B31l, V0 = $15, p=0.438$ ). In contrast, oscillations in heterologous neurons were significantly delayed (i.e., positive phase lag) relative to the ipsilateral (i) B63 partner (filled dots and boxes; B31/B63i, V0 $=78, p=0.0005$; B30/B63i, V0 $=35, p=0.016)$. 
bioRxiv preprint doi: https://doi.org/10.1101/2021.03.30.437701; this version posted March 31, 2021. The copyright holder for this preprint (which was not certified by peer review) is the author/funder, who has granted bioRxiv a license to display the preprint in perpetuity. It is made available under aCC-BY 4.0 International license.

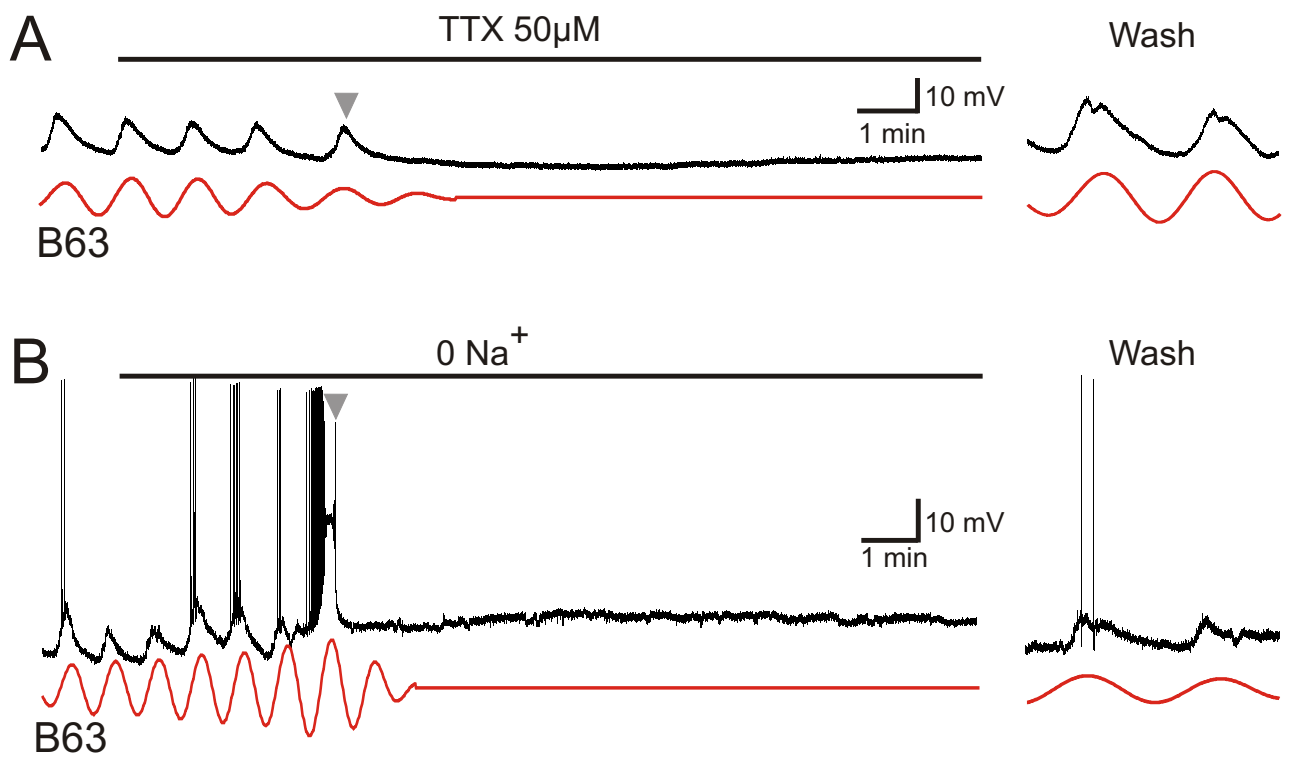

Wash

Wash

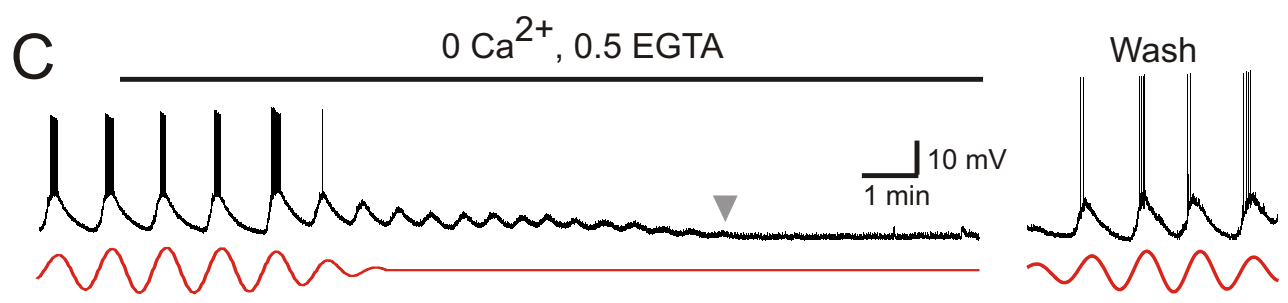

B63
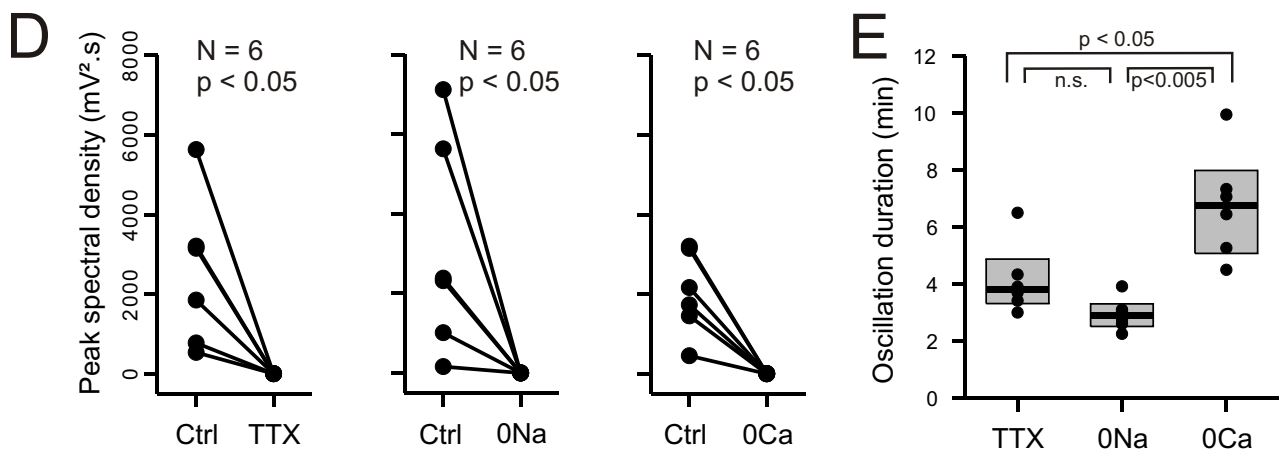

Figure 8. Involvement of sodium and calcium ions in the voltage oscillation.

(A-C) Under chemical synapse blockade, the spontaneous voltage oscillations of B63 neurons were reversibly (trace excerpts at right) suppressed by bath application of $50 \mu \mathrm{M}$ tetrodotoxin (A, horizontal line), sodium-free ( $B$, horizontal line) or calcium-free salines ( $C$, horizontal line). Red traces: reconstructed waveforms from corresponding peak spectral densities.

(D) Group quantification under the experimental conditions illustrated in A-C: The amplitude of the dominant oscillation in Low $\mathrm{Ca}+\mathrm{Co}$ saline alone (Control, Ctrl) was significantly reduced after application of TTXcontaining (left, $V=-21, p=0.031$ ), Na-free (middle, $V=-21, p=0.031$ ), or calcium-free saline (right, $V=-21, p$ $=0.031)$.

(E) Inter-group comparison of oscillation longevity (grey arrowheads in A-C) after modified-saline perfusion onset $(H=11.684, p<0.005)$. B63's oscillation persisted for significantly longer after removal of extracellular calcium $(0 \mathrm{Ca}+0.5 \mathrm{EGTA}, \mathrm{N}=6)$ than after blockade of sodium channels by TTX $(N=6, q=4.625, p=0.013)$ or in the absence of extracellular $\mathrm{Na}(\mathrm{N}=6, \mathrm{q}=8.092, \mathrm{p}<0.005)$. No significant difference was evident between the effects of sodium channel blockade or Na removal $(q=-3.468)$. 
A

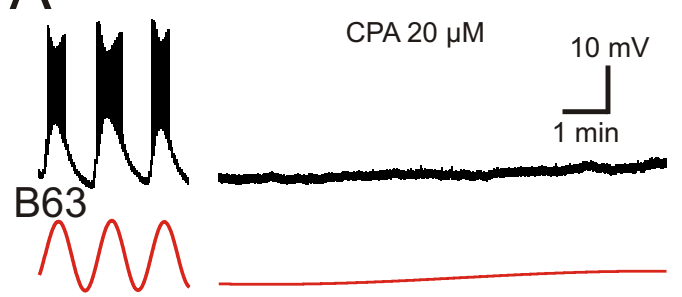

C

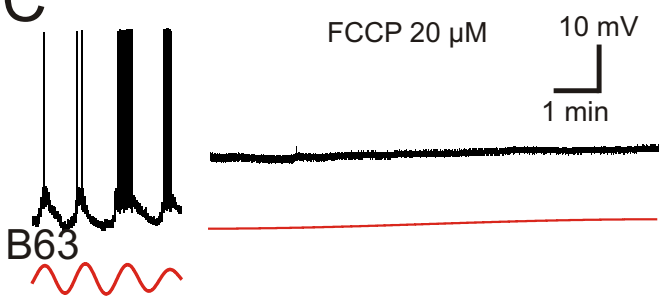

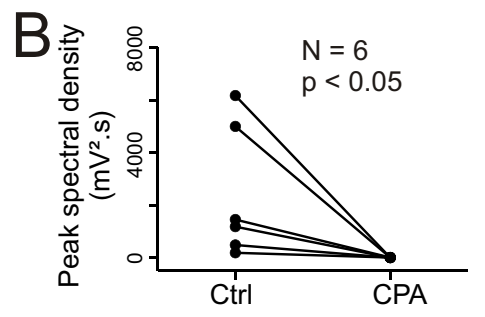

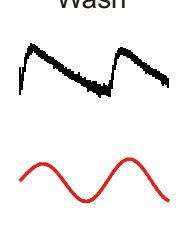

Wash

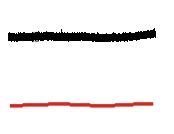

$\mathrm{D}$

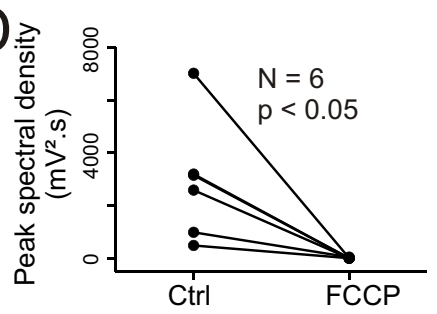

Figure 9. Involvement of intracellular calcium stores in the voltage oscillation.

(A) The spontaneous voltage oscillation of a B63 neuron (left excerpt) was reversibly (right excerpt) suppressed in the presence of $20 \mu \mathrm{M}$ CPA, a SERC inhibitor (middle excerpt, recorded 20 min after the beginning of drug application).

(B) Group analysis showing a significant reduction in oscillation magnitude of 6 B63 neurons measured before (Ctrl) and 20 min after the beginning of CPA application ( $V=21, p=0.031)$.

(C) Suppression of B63 oscillation by application of $20 \mu \mathrm{M}$ FCCP, an uncoupler of mitochondrial oxidative phosphorylation leading to calcium release. The neuron's spontaneous oscillation (left) was irreversibly (right) suppressed and the cell depolarized (middle, recorded $20 \mathrm{~min}$ after the beginning of drug application).

(D) The oscillation magnitudes (Ctrl) of 6 tested B63 neurons were significantly reduced $(V=21, p=0.031)$ after 20 min of FCCP application. 
A

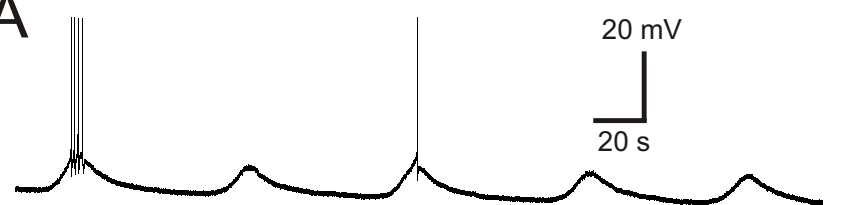

B63

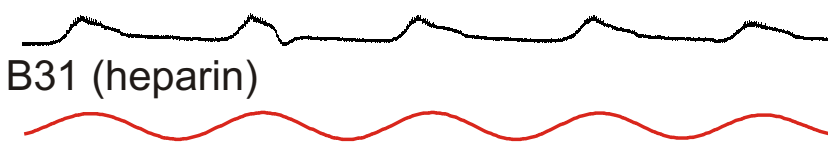

C

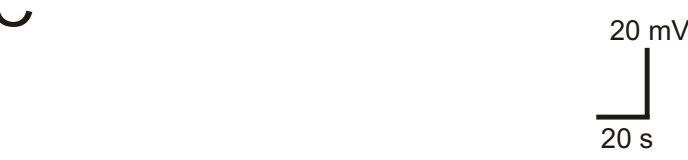

B63 (heparin)

\section{B31}

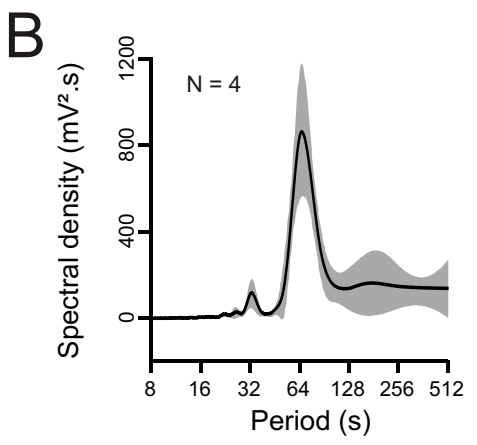

$\mathrm{D}$

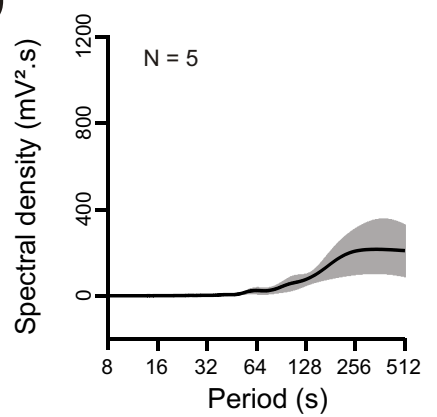

Figure 10. The voltage oscillation generated by intracellular calcium store release is specific to B63.

(A,C) Paired recordings of B63 and B31 neurons under chemical synapse blockade, 30 min after the beginning of an intrasomatic injection of the ER membrane calcium channel blocker heparin $(20 \mathrm{mg} / \mathrm{ml})$ into either the bilateral B31 (A) or bilateral B63 (C) neurons. Heparin in B31 had no effect on the ongoing oscillation of an un-injected B63 cell (A), but suppressed oscillations in both a B63 and an un-injected B31 (C) after injection into both B63 neurons. Red traces: reconstructed waveforms from the corresponding periodograms.

(B,D) Average power spectra obtained $30 \mathrm{~min}$ after the beginning of bilateral intracellular heparin injection into the B31 (B) or B63 neurons (D) in 4 and 5 preparations, respectively. 
bioRxiv preprint doi: https://doi.org/10.1101/2021.03.30.437701; this version posted March 31, 2021. The copyright holder for this preprint (which was not certified by peer review) is the author/funder, who has granted bioRxiv a license to display the preprint in perpetuity. It is made available under aCC-BY 4.0 International license.
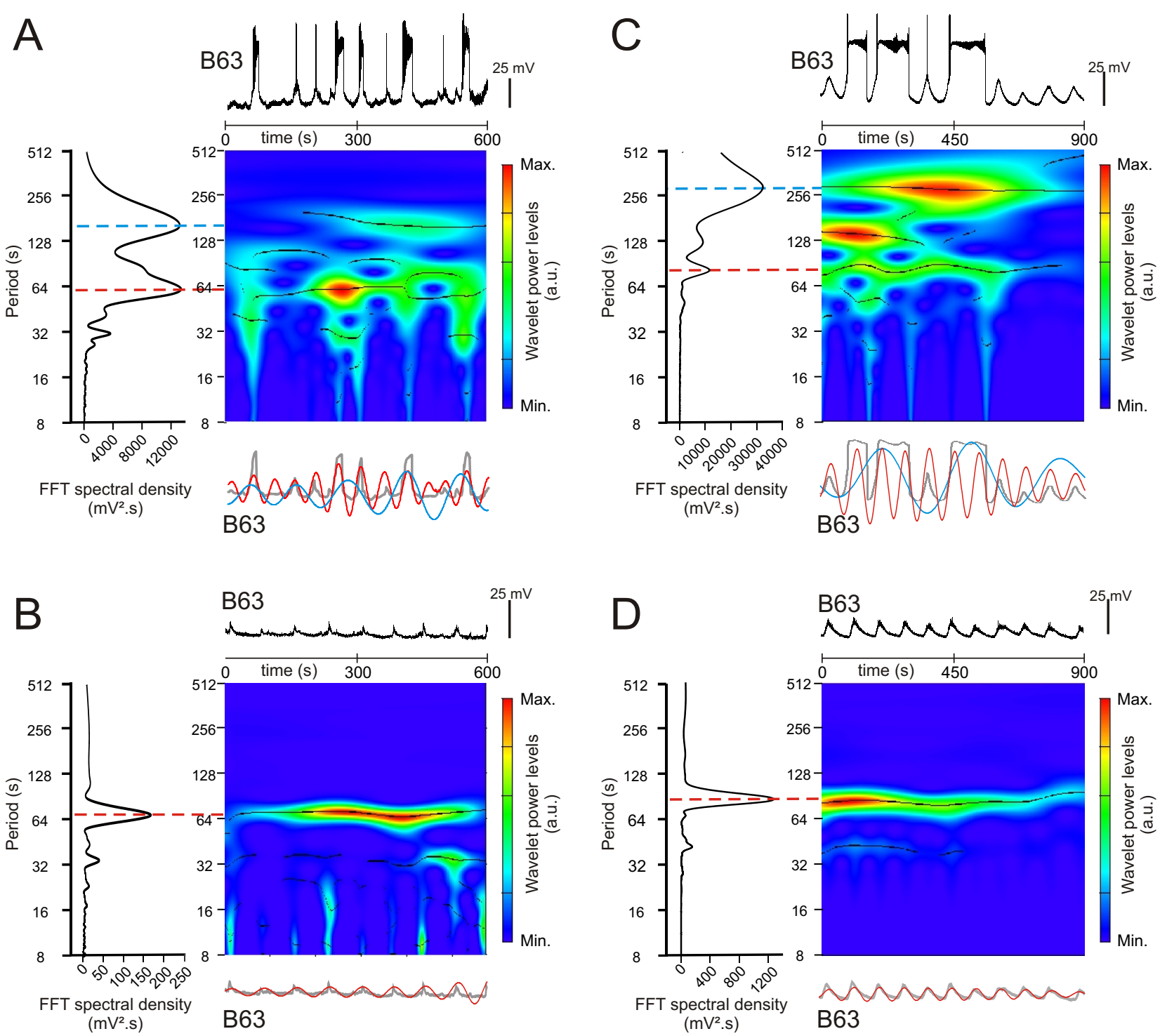

\section{Supplemental Figure 1. Spectral density analysis of B63 neuron intracellular recordings.}

A,B. Analysis under normal saline (ASW) conditions. Colored panels (middle) are wavelet-based power spectral decompositions of the membrane potential variations over time in the B63 cell recording excerpt shown at top (Color code bars: power; black lines: ridges of power). Plots at left are periodograms from Fast Fourrier Transform (FFT) of the same intracellular recordings used to quantify spectral densities (i.e., amplitudes) at dominant periods (indicated by red and blue lines) of voltage changes in the period range between 8 and $512 \mathrm{~s}$. Note that event period (in secs) rather than its reciprocal (frequency) was used in the time domain due to the very slow spontaneous rates of membrane potential fluctuations (see Materials and Methods). Bottom traces are mathematically-reconstructed oscillations from the dominant periods revealed in the FFT periodograms (red and blue traces) superimposed with the corresponding intracellular recording excerpt after low pass filter smoothing to remove action potentials (gray traces). The recordings in A and B, and corresponding wavelet power spectra, periodograms and reconstructed oscillations, are from the same B63 neuron with $(A)$ or without $(B)$ the spontaneous expression of plateau potentials, as reported in Figure 2 .

C,D. Equivalent analysis under Low $\mathrm{Ca}+\mathrm{Co}$ saline conditions to block chemical synapses. The intracellular recordings (Top traces) and corresponding wavelet and FFT power spectral decomposition and reconstructed waveforms are from the same B63 neuron with (C) or without (D) spontaneous plateau potential generation, as reported in Figure 3. 
bioRxiv preprint doi: https://doi.org/10.1101/2021.03.30.437701; this version posted March 31, 2021. The copyright holder for this preprint (which was not certified by peer review) is the author/funder, who has granted bioRxiv a license to display the preprint in perpetuity. It is made available under aCC-BY 4.0 International license.

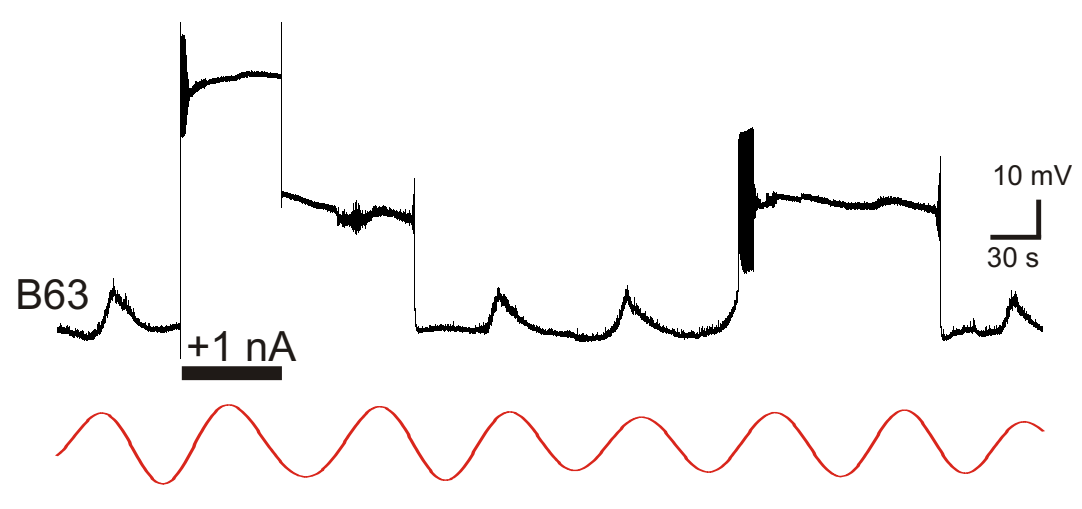

\section{Supplemental Figure 2. B63 plateau potentials expressed with chemical synapses blocked.}

Intracellular recording of a B63 neuron in a buccal ganglion under bath-applied Low Ca+Co saline. A transient intracellular injection of depolarizing current (horizontal bar, $+1 \mathrm{nA}$ ) elicited a prolonged plateau potential that was similar to a subsequent plateau triggered spontaneously on a depolarizing phase of ongoing membrane potential oscillation. The red trace is the corresponding reconstructed waveform from the peak spectral density; period $71 \mathrm{~s}$. 


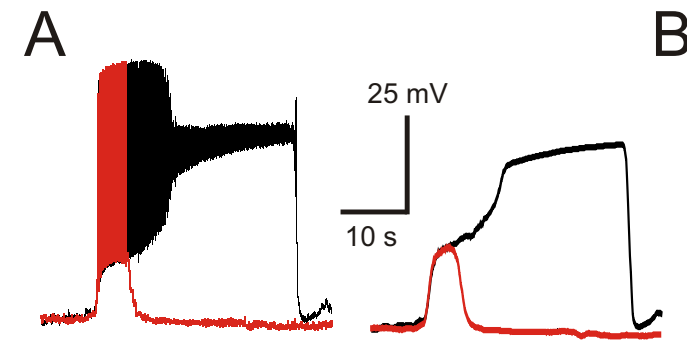

B63

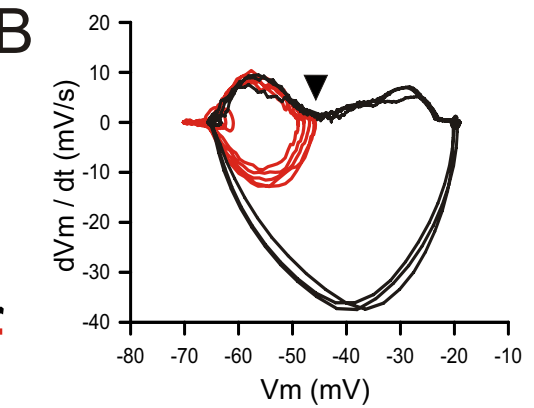

Supplemental Figure 3. B63's voltage oscillation triggers plateau potentials under normal saline (ASW) conditions.

A. Left: superposition of an oscillation cycle without a plateau (red trace) and one leading to a plateau (black trace) recorded in the absence of chemical synapse blockade. Right: same traces after low-pass filtering to remove action potentials.

B. Phase-plane plot of 8 successive oscillation cycles both without ( 5 cycles; red), and with ( 3 cycles; black) plateau potential generation in the same B63 neuron. The arrowhead indicates the voltage threshold for plateau potential generation. 

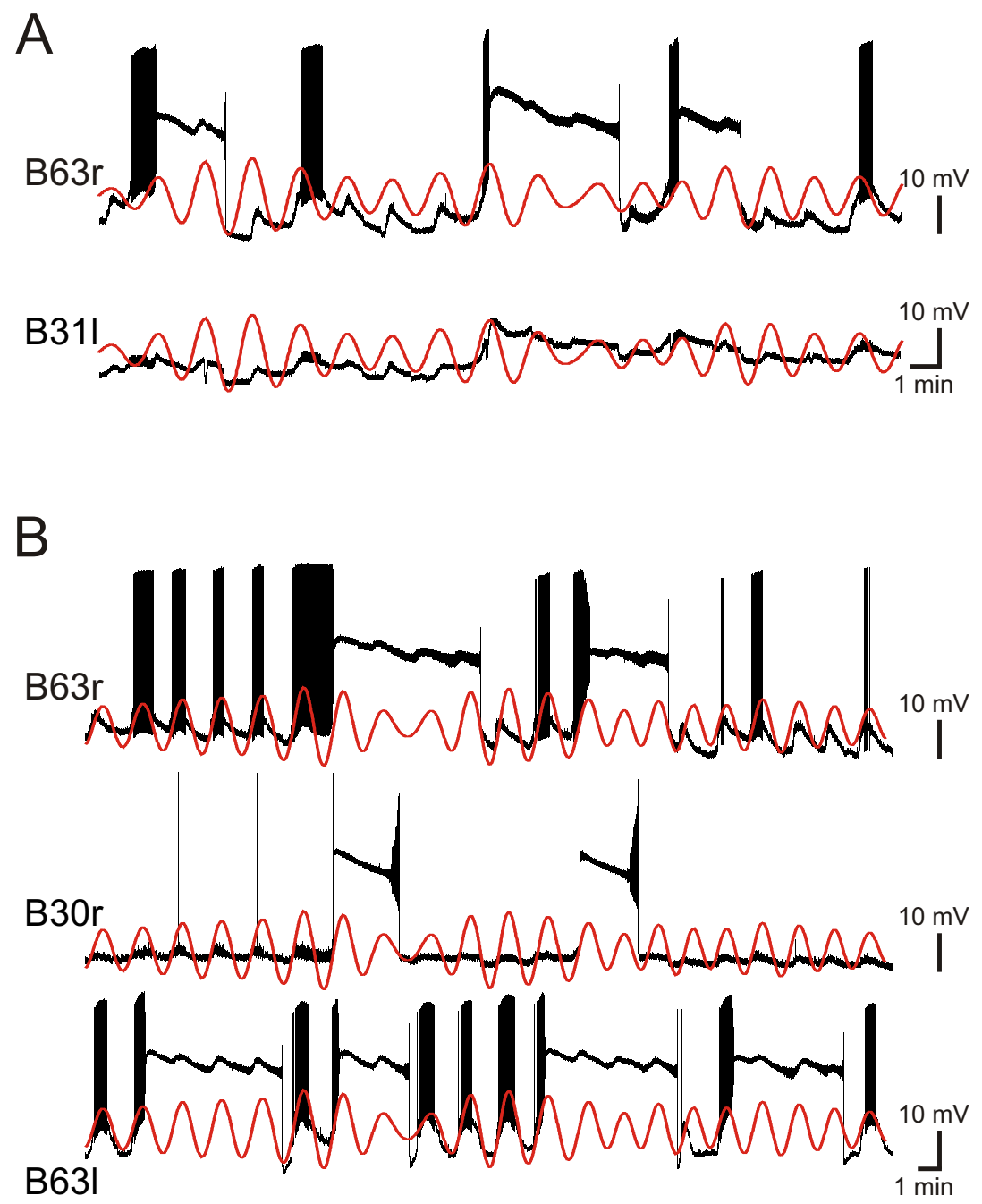

\section{Supplemental Figure 4. Irregular plateau potentials triggered by regular voltage oscillations in electrically-coupled network neurons.}

A. Paired intracellular recordings from two gap junction-coupled neurons (right B63 and left B31) under chemical synapse blockade. In contrast to the continuous synchronous and rhythmic depolarizations (see red traces, which are the reconstructed voltage oscillation of B63 superimposed with both the raw B63 and B31 recordings), the production of plateau potentials was irregular and occurred independently in the two neurons.

B. Simultaneous recordings from three gap junction-coupled neurons (right B63, right B30 and left B63) under chemical synapse blockade. All three cells expressed synchronous, rhythmic depolarizations (red traces: reconstructed voltage oscillation of right $\mathrm{B} 63$ superimposed with all raw recordings), but again, the onsets and terminations of plateau potentials were highly irregular within and between the individual neurons. 
A Low $\mathrm{Ca}+\mathrm{Co}$

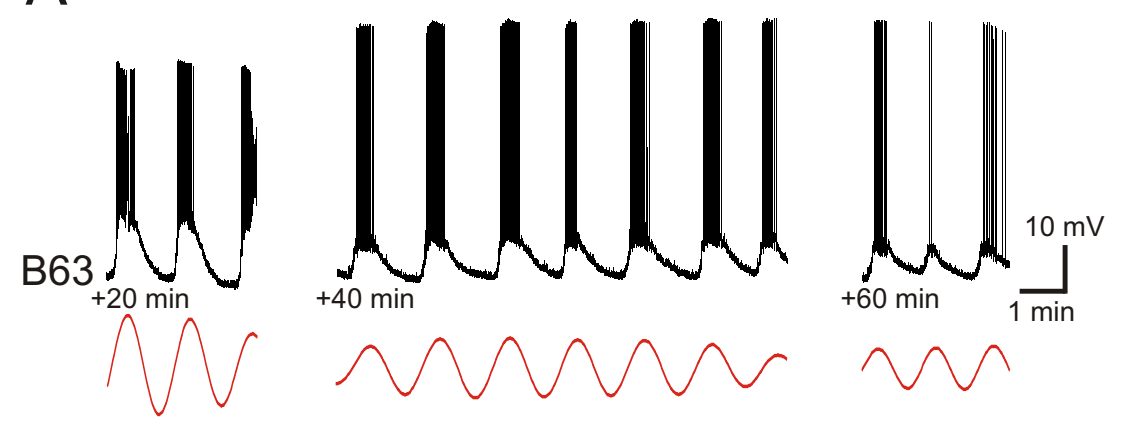

B Low $\mathrm{Ca}+\mathrm{Co}+\mathrm{DMSO}$ 0.5\%
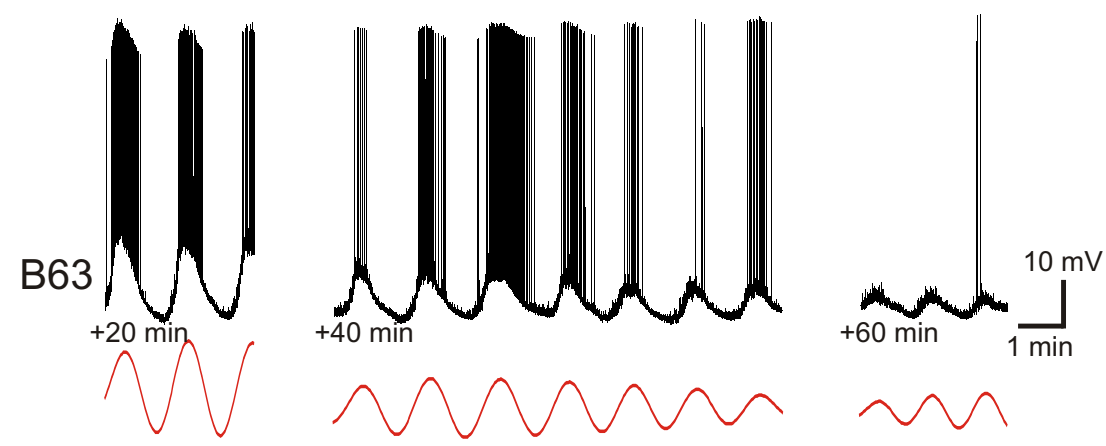

C

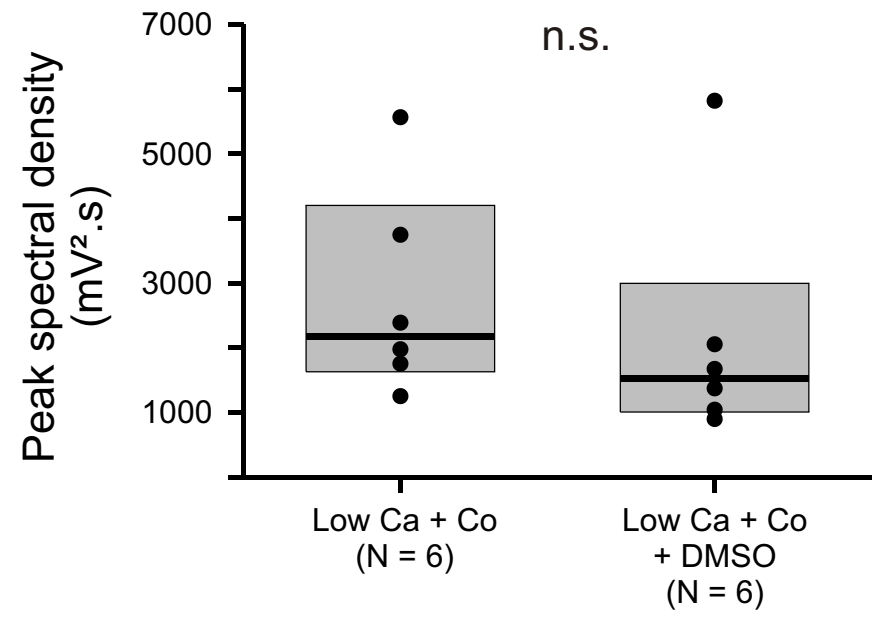

\section{Supplemental Figure 5. The voltage oscillation of B63 is unaffected by exposure to DMSO.}

A,B. Recordings from two different B63 neurons during bath-application of Low Ca+Co saline alone (A) or additionally containing $0.5 \%$ DMSO (B). Left trace excerpts: 20 min after the beginning of the perfusion. Middle traces: $40 \mathrm{~min}$ after perfusion onset. Right traces: $60 \mathrm{~min}$ after perfusion onset. Red traces: reconstructed waveforms from the corresponding peak spectral densities.

C. Group comparison of oscillation magnitudes in $\mathrm{B} 63$ cells measured from 20 until 30 min after the beginning of saline perfusion in the absence (left) and presence of $0.5 \%$ DMSO (right). DMSO had no significant (n.s.) effect on the amplitudes of the voltage oscillations (Mann-Whitney rank sum test: $V=25, p=0.310$ ). 